VIBRANT SEGUES: INVISIBLY VACANT STOREFRONTS, TACTICAL URBANISM AND HOW EMBRACING FAILURE MAY BENEFIT THE URBAN PLANNING PROFESSION

by

Rudra Sarkar, BIB, Carleton University, 2004

\author{
A Major Research Paper \\ presented to Ryerson University \\ in partial fulfillment of the requirements for the degree of \\ Master of Planning \\ in \\ Urban Development
}

Toronto, Ontario, Canada, 2012

(C) Rudra Sarkar 2012 


\section{AUTHOR'S DECLARATION}

I hereby declare that I am the sole author of this major research paper.

This is a true copy of the major research paper, including any required final revisions, as accepted by my examiners.

I authorize Ryerson University to lend this major research paper to other institutions or individuals for the purpose of scholarly research.

I further authorize Ryerson University to reproduce this major research paper by

photocopying or by other means, in total or in part, at the request of other institutions or individuals for the purpose of scholarly research.

I understand that my major research paper may be made electronically available to the public. 


\title{
VIBRANT SEGUES: INVISIBLY VACANT STOREFRONTS, TACTICAL URBANISM AND HOW EMBRACING FAILURE MAY BENEFIT THE URBAN PLANNING PROFESSION
}

(C) Rudra Sarkar 2012

\author{
Master of Planning \\ in \\ Urban Development \\ Ryerson University
}

\begin{abstract}
Tactical urbanism initiatives working to combat the presence of vacant storefronts are not yet commonly found in Canadian cities. This paper reports on an interview study investigating the potential for tactical urbanism to enhance the vibrancy of commercial corridors in Toronto, Canada, and how such an initiative may affect a variety of potential stakeholders as well as its compatibility with municipal governance and planning practice. Results show popularity of concept amongst potential stakeholders, the need for changes to provincial legislation and the evolving role of the Toronto planning professional to tap into the experimental enthusiasm of local community players.
\end{abstract}

Key words:

tactical urbanism; vacant storefronts; Toronto. 


\section{ACKNOWLEDGEMENT}

I owe Pamela Robinson and Steven Webber a debt of gratitude for taking the time to be my MRP Supervisor and 2nd Reader, respectively, during a busy and hectic time. 


\section{TABLE OF CONTENTS}

\begin{tabular}{|c|c|c|}
\hline AUTHOR'S DECLARATION & & ii \\
\hline ABSTRACT & & iii \\
\hline ACKNOWLEDGEMENT & & iv \\
\hline LIST OF ILLUSTRATIONS & & vi \\
\hline LIST OF APPENDICES & & vii \\
\hline 1.0. TORONTO'S VACANT STOREFRONTS & ARE THEY A PROBLEM? & 1 \\
\hline 1.1. AN INTRODUCTION TO TACTICAL URBANISM & & 5 \\
\hline 2.0. OBJECTIVE OF STUDY & & 8 \\
\hline 2.1 RESEARCH QUESTIONS & & 9 \\
\hline 2.2 STUDY DESIGN \& METHOD & & 10 \\
\hline 3.0. A REVIEW OF THE LITERATURE & & 13 \\
\hline 3.1. ORIGINS OF TACTICAL URBANISM & The Post-Soviet experimenters & 13 \\
\hline 3.2. THE CAUSES OF STOREFRONT VACANCIES & & 15 \\
\hline 3.3. WHY VACANT STOREFRONTS ARE A PROBLEM & & 20 \\
\hline $\begin{array}{l}\text { 3.4. THE OPEN-SOURCE NATURE OF TACTICAL } \\
\text { URBANISM }\end{array}$ & & 24 \\
\hline 3.5. URBAN VIBRANCY & The 'People' Variable & 27 \\
\hline 3.6. INCLUSIVE REVITALIZATION & & 30 \\
\hline 3.7. A THEORETICAL BASIS & From Strategic Planning to Tactical Planning & 34 \\
\hline 3.8. CONCLUSION OF REVIEW & & 38 \\
\hline 4.0. REVIEW OF PRACTICE & & 41 \\
\hline 4.1. NEWCASTLE-AUSTRALIA'S DETROIT? & & 41 \\
\hline 4.2. MARCUS WESTBURY'S "RENEW NEWCASTLE" & & 42 \\
\hline 4.3. HOW IT WORKS ... & & 44 \\
\hline 4.3.1. Intermediary Space Broker & & 44 \\
\hline 4.3.2. Licenses not Leases & & 45 \\
\hline $\begin{array}{l}\text { 4.4. HOW RENEW NEWCASTLE EVALUATES } \\
\text { SUCCESS }\end{array}$ & & 46 \\
\hline 4.5. PRACTICE - What has worked in other locations & & 49 \\
\hline 4.6. CONCLUSION OF REVIEW & & 50 \\
\hline 5.0. TACTICAL URBANISM & Seeking opportunity in the idle interim & 53 \\
\hline 5.1. BARRIERS TO ENTRY & What holds Tactical Urbanism back? & 57 \\
\hline 5.1.1. Regulation & & 58 \\
\hline 5.1.2. Property Owners & & 59 \\
\hline 5.1.3. Systemic Externalities & & 59 \\
\hline 6.0. THE TORONTO PERSPECTIVE & & 61 \\
\hline 6.1. INTERVIEWS & & 61 \\
\hline 6.2.1. CONCEPT FAMILIARITY & & 62 \\
\hline 6.2.2. $\quad$ CITYWIDE ORGANIZATIONS & & 62 \\
\hline 6.2.3. $\quad$ VACANT PROPERTY OWNERS & & 64 \\
\hline 6.2.4. BUSINESS OWNERS & & 65 \\
\hline 6.2.5. BUSINESS ASSOCIATIONS & & 66 \\
\hline 6.2.6. CREATIVE ASSOCIATIONS & & 67 \\
\hline 6.3. FINDINGS & & 69 \\
\hline $\begin{array}{ll}\text { 7.0. } & \text { ADDRESSING THE RESEARCH QUESTIONS } \\
\end{array}$ & & 72 \\
\hline 8.0. RECOMMENDATIONS & FOR FUTURE RESEARCH AND PRACTICE & 79 \\
\hline 9.0. CONCLUSION & & 82 \\
\hline 10.0. APPENDICES & & 84 \\
\hline 11.0. REFERENCES & & 94 \\
\hline
\end{tabular}




\section{LIST OF ILLUSTRATIONS}

\begin{tabular}{|c|c|c|}
\hline 1 & East Berlin's Mainzer Strasse in 1990 & 14 \\
\hline 2 & Four forms of Retail Blight & 18 \\
\hline 3 & Urban Acupuncture & 25 \\
\hline 4 & The 'People' Variable & 28 \\
\hline 5 & Urbanism Spectrum & 35 \\
\hline 6 & Newcastle's main 'Hunter Street' strip, prior to Renew Newcastle's intervention & 41 \\
\hline 7 & Renew Newcastle in the process of revitalizing empty storefronts & 43 \\
\hline 8 & Lonely Planet listing & 47 \\
\hline 9 & 805 Queen Street West, Toronto & 54 \\
\hline 10 & Woodward Avenue in Downtown Detroit & 56 \\
\hline 11 & Queen Street West, Toronto & 61 \\
\hline
\end{tabular}




\section{LIST OF APPENDICES}

\begin{tabular}{|c|c|c|c|}
\hline 10.1. & Appendix 1 & Section 331 of the City of Toronto Act, 2006 & 84 \\
\hline 10.2. & Appendix 2 & Section 364 of the Ontario Municipal Act, 2001 & 87 \\
\hline 10.3. & Appendix 3 & $\begin{array}{l}\text { NOTICE OF MOTION - Re-designing the Commercial Tax Relief program as a strategic tax } \\
\text { incentive to stimulate economic development - by Councillor Mike Layton }\end{array}$ & 90 \\
\hline 10.4. & Appendix 4 & $\begin{array}{l}\text { Economic Development Committee consideration on September 14, } 2011 \text { - } \\
\text { Re-designing the Commercial Tax Relief Program as a Strategic Tax Incentive to Stimulate } \\
\text { Economic Development }\end{array}$ & 92 \\
\hline 10.5 . & Appendix 5 & NOTICE OF MOTION - 'Unfinished Business' - by Councillor Paula Fletcher & 94 \\
\hline
\end{tabular}


"The remarkable intricacy and liveliness of downtown can never be created by the abstract logic of a few men. Downtown has had the capability of providing something for everybody only because it has been created by everybody. So it should be in the future; planners and architects have a vital contribution to make, but the citizen has a more vital one. It is his city, after all; his job is not merely to sell plans made by others, it is to get into the thick of the planning job himself.

What a wonderful challenge there is! Rarely before has the citizen had such a chance to reshape the city, and to make it the kind of city that he likes and that others will too. If this means leaving room for the incongruous, or the vulgar or the strange, that is part of the challenge, not the problem.

Designing a dream city is easy; rebuilding a living one takes imagination."

-'Downtown is for people.' Jane Jacobs (1958, p184)

"And Now for Something Completely Different..."

-Monty Python's Flying Circus

\subsection{TORONTO'S VACANT STOREFRONTS - ARE THEY A PROBLEM?}

The genesis of this paper may be traced to a short assignment undertaken during an internship at Toronto City Hall by the author in 2011. The presence of vacant commercial storefront properties in a specific area of Toronto were considered and the potential for activating such temporarily disused spaces investigated, in order to enhance the vibrancy of the streets. Research conducted during this internship culminated in the composition of the Motion found in Appendix 3, Section 10.3., as well as its subsequent Motion to Refer found in Appendix 4, Section 10.4.

For 2011, the storefront vacancy rate in the urban core of Toronto stood at $9 \%$ (Cushman \& Wakefield, 2012), which is not an excessively high rate in comparison with 
other cities in North America ${ }^{1}$. One representative from an organization that coordinates with Business Improvement Associations throughout Toronto states that around $80 \%$ of all storefronts in the city are owned by absentee landlords—which in some instances, this representative argued, could lend itself to an out of sight, out of mind mentality, potentially precluding involvement in local area concerns regarding street vitality; a situation merchants with whom he works feel negatively affects their neighbouring businesses. This opinion must be tempered with the understanding that there do exist storefront property owners in Toronto, however 'absentee', who maintain involvement in local Business Improvement Area (BIA) organizations, striving to enhance corridor vibrancy, while attempting to maximize their real estate investments.

What must be acknowledged, at the start of this paper, is that the Toronto of 2012 does not suffer from the levels of retail blight and commercial corridor dereliction of entire districts such as found in many inner cities in the United States. Toronto is well known for the vibrant pedestrian activity of its urban core. Unlike many large American urban cores, Toronto's downtown is said to be "a dynamic, mutable neighbourhood where hundreds of thousands of people—and more every day—now work, play and, most importantly, make their home" (McBride, 2010). Taking this into account, what this paper seeks to consider is the question of temporal opportunities that exist in all commercial corridors—and the potential marginal affects that idle storefronts may have. Are tactical urbanism initiatives in storefront retail effective as a collaborative urban planning tool merely for the

\footnotetext{
1 "vacancy rates in relatively healthy retail markets typically range from 5 percent to 10 percent" (Michael Brandman Associates, 2011, p 3.18-5)
} 
revitalization of the most extreme dereliction of commercial corridors, or might they function with similar effectiveness for the sustained stability of relatively functional ones?

Stability in this regard references the management of the disruptive cycles of retail storefront occupancy. With this in mind, it must be remembered that even the most vibrant of commercial corridors can experience vacancies at any given point in time. These episodes of inactivity may be argued to have both the potential for diminished vibrancy as well as the potential for tactical opportunity — depending on the perspective one takes. One single empty storefront may not be said to represent 'blight' but arguably does contribute to a diminished aggregate vibrancy—perhaps what may be considered 'marginal blight.' These episodes of inactivity—however short in duration—offer the opportunity, even in healthy urban cores such as found in Toronto, for enterprise incubation and experimentation —of the embrace of failure, referenced in the title.

Currently no tactical initiatives with a citywide scope exist to counteract the effects of vacant storefronts in Toronto. Unfortunate obstacles within the province of Ontario are two legislations_-section 364 of the Ontario Municipal Act (2001) (found in Appendix 2, on page 87 of this paper) and Section 331 of the City of Toronto Act (2006); the latter applicable solely to the City of Toronto (found in Appendix 1, on page 84 of this paper), which call for Ontario municipalities to provide a $30 \%$ property tax discount to commercial properties vacant for longer than 90 days. In the year 2010, the City of Toronto saw $\$ 20 \mathrm{M}$ of potential revenue forgone from this Vacant Commercial Tax Relief program (City of Toronto Budget Committee, 2010). Marcus Westbury (2012), the leader of a successful Australian tactical urbanism venture, finds this reality perplexing, working 
as it is, at cross-purposes to the incentivization of vibrant commercial corridors, and the potential incubation of future generations of successful local enterprises; explaining, that a program to penalize any extended shuttering of vacant storefronts would make more sense.

Municipal policymakers in Toronto are beginning to take notice. In July of 2011, City Councillor Mike Layton filed the above-mentioned motion (see Appendix \#3 and Appendix \#4, on pages 90 and 92 of this paper) seeking to redesign the Vacant Commercial Tax Relief program. The aim of this motion was to create more of an incentive to stimulate economic development from the provision of vacant storefronts for enterprise incubation rather than having owners of vacant property benefit financially while commercial strips potentially experienced further decline from the contagion effects of such vacancies.

Relevant as well to this discussion, City Councillor Paula Fletcher filed a motion (see Appendix \#5, on page 94 of this paper) in April of 2012 which sought to expedite development projects, by setting restrictions on the time within which construction /demolition /renovation must move forward, so properties do not sit idle and inaccessible, for extended periods of time, after municipal approval (Fletcher, 2012). Although measures such as these strategic, governmental, efforts will go a long way to assist with establishing a tactical urbanism initiative in Toronto, it is well to note that at the time of writing both of the above two motions remain under study and have not been implemented. 


\subsection{AN INTRODUCTION TO TACTICAL URBANISM}

The revitalization or stabilization of central urban areas, districts, or individual properties, is a significant aspect of the practice of urban planning. Participatory planning initiatives, as they have for the past several decades, manifest collaborative city-building values through the engagement and empowerment of local-area stakeholders in the process of urban change. The temporary activations of vacant—or derelict—storefront properties, by local participants, with the objective of counteracting the marginally negative effects such vacancies may have on the vibrancy of the adjacent neighbourhood, while simultaneously creating experimental enterprise opportunities, exemplifies such collaborative values. The concept of 'urban vibrancy' within this context has been qualitatively defined by the American organization ArtPlace², as "attracting people, activities and value to a place and increasing the desire, and the economic opportunity, to thrive in a place" (ArtPlace, 2011, p1).

For many years of the $20^{\text {th }}$ century, Toronto, as with most large North American conurbations, was planned and developed with a focus on growth and expansion. During this era, prior to today's more decentralized and informal methods of city building, orthodox models of urban planning served almost solely to anticipate and administer these growth stages of metropolitan areas (Earls, 2011; Blumner, 2006). These more traditional and bureaucratic urban planning frameworks have been less effective in addressing and managing causal elements of retail property vacancy and diminished vibrancy of neighbouring communities (Overmeyer, 2007; Blumner, 2006). Recent initiatives

\footnotetext{
2 ArtPlace is a collaboration composed of the American National Endowment for the Arts, major foundations
} and various federal agencies. 
investigate intermediary stages to the regular market occupancy and use of these properties—such as urban stagnation, urban shrinkage, and speculative real estate investment, while attempting to facilitate the collaborative action of local stakeholders who are affected by such circumstances and seek to reverse or alter them (Earls, 2011).

Tactical urbanism is a form of planning intervention within the intermediate timeframe spoken of above. Mike Lydon et al. define tactical urbanism as an intervention with the following characteristics:

1. "A deliberate, phased approach to instigating change."

2. "The offering of local solutions for local planning challenges."

3. "Short-term commitment and realistic expectations."

4. "Low-risks, with possibly high reward."

5. "The development of social capital between citizens and the building of organizational capacity between public-private institutions, non-profits, and the constituents."

(Lydon et al., no date., p1)

Although tactical urbanism may refer to temporary activation initiatives of a variety of property types, built and un-built (i.e., undeveloped spaces), this paper will focus on activations practiced along built retail corridors, involving informal actors implementing unorthodox solutions to maintain activity within vacant storefront properties for short periods of time. These periods, to be discussed later in this paper, may be for as short as 30-days arrangements. Such initiatives bring together local stakeholders-represented by 
community organizations, the creative community, small business start-ups, hobbyists, cottage industries as well as the owners of the vacant properties—-for a shared purpose. Together these participants seek to enhance or stabilize the vibrancy of a neighbourhood commercial corridor-through preventing or reversing the effects of vacant storefronts, while simultaneously creating opportunities for the incubation of experimental startup enterprises. Tactical urbanism is a versatile, responsive method to changing urban conditions while making better, more productive use of erstwhile vacant properties (Graham, 2012).

Shelagh Graham notes a list of purposes served by tactical urbanism that are commonly asserted by its proponents, referenced from a variety of sources:

"...increasing the diversity of people participating in the planning process (Haydn, 2006; Mackey, 2007; Blumner, 2006), creating opportunities for new directions and for challenging the status quo (Cumberlidge \& Musgrave, 2007; Temel, 2006), attracting interest (and people) to a site (Blumner, 2006; Overmeyer, 2007), creating employment opportunities (Overmeyer, 2007; Cumberlidge \& Musgrave, 2007), and providing incubator space for new entrepreneurs (Mackey, 2007; Overmeyer, 2007; Gerend, 2007)" (Above as cited in Graham, 2012, p3). Additionally, owners of vacant properties may benefit from having their spaces occupied and maintained during transitions between ownership or tenancy. Short-term occupancy of such property has the potential to prevent vandalism and disrepair while fostering an atmosphere of vibrant location. 


\subsection{OBJECTIVE OF STUDY}

This paper is inspired by the application of collaborative, community-organized planning and revitalization ideals. People and organizations concerned and involved with addressing the specific issue of increasing storefront vacancies are implementing principles of tactical urbanism in order to take the initiative to counteract the effects of these occurrences within their local neighbourhood commercial corridors.

With planning initiatives today expected to be more participatory and community-led in scope, questions arise as to the level of municipal governmental involvement necessary to foster such programs.

As with all applications of collaborative planning interventions, the recognition and involvement of the many stakeholders who may be affected, concerned, or seeking to participate, is a vital aspect of a successful and ethical planning practice. This paper will explore the potential for the application of tactical urbanism initiatives in Toronto, Canada; addressing the specific concern of storefront vacancies. Although a common urban revitalization tool in certain European and Australian jurisdictions, Toronto currently lacks an organized, citywide storefront activation umbrella organizationwhether municipally led or non-governmental in scope. This research project will assess the practical barriers and opportunities for tactical urbanism in Toronto, in the context of establishing such programming, with the goal of offering recommendations to overcome the obstacles that may be encountered and providing the tools and resources available for facilitating the process. 


\subsection{RESEARCH QUESTIONS}

This project seeks to develop research about how to stabilize or revitalize commercial corridors, enhance neighbourhood vibrancy and provide opportunities for entrepreneurial start-ups by drawing from the experience of other vacant storefront tactical urbanism initiatives from outside Toronto. This project will address the following research questions:

- Which stakeholders are affected positively and/or negatively from such revitalization efforts and might they be involved in their implementation?

- What are some best practices in the effective operation of tactical urbanism programs?

- What Toronto-specific factors help or hinder the implementation of temporary storefront reactivation projects?

- What implications may tactical urbanism initiatives have on planning policy, municipal regulations? (and vice versa)

With the application of more inclusive methods of planning practice becoming more prevalent throughout North American municipalities, it is an exciting and opportune time to investigate the possibility of the introduction of a grassroots urban revitalization scheme in the largest city in Canada. 


\subsection{STUDY DESIGN \& METHOD}

This paper begins with a discussion of the origins of tactical urbanism. Next it moves to a review of secondary literature in order to establish a comprehensive foundation of current knowledge of this evolving practice of city building focusing on the review of scholarly peer-reviewed articles with a focus on temporary use of vacant storefronts as a solution to commercial corridor disruptions or decline. A literature review reports the findings from this investigation. Following this, a well known, successful and oft-cited case of such an initiative is explored. The innovation of tactical urbanism is then exploredevaluating its theoretical underpinnings, history as well as challenges for the future.

The interpretive social science approach is implemented for the field research component of this project. Neumann (2011) explores the foundation of this field of research, describing how although there exist a variety of forms of interpretive social sciences, this approach has become generally referred to as 'qualitative research,' due to the field research and interviews conducted for the investigation of a research objective. Neumann (2011) explains that Interpretive research differs from Positivist research with its sole use of qualitative analysis rather than involving any quantitative investigation. This research project is based upon the interpretive approach, as understood by "the systematic analysis of socially meaningful action through the direct detailed observation of people in natural settings in order to arrive at understandings and interpretations of how people create and maintain their social worlds" (Neumann, 2011, p101-102).

For this research project semi-structured interviews were conducted with individuals who experience, or are involved with dealing with, the issues of storefront vacancies on 
commercial corridors in Toronto as well as those with potential expertise on the subject at a larger, citywide or theoretical scale. Experiences, opinions and location-specific issues with regard to the challenges and opportunities of tactical initiatives within storefront vacancies were sought in order to understand whether experiences outside of Toronto might be replicated. Two specific commercial corridors in Queen West and Queen East were selected, due to their both being located along the same streetcar route equidistant from the Yonge-Queen intersection. This high-rent, central intersection is the most commercially vibrant section along Queen Street, both today as well as historically (Flack, 2011).

The specific neighbourhood corridors were selected for the following aspects of equivalence: ease of access (streetcar), distance from the Yonge-Queen intersection, and similar local built form. Selection of study participants occurred through telephone, email and direct conversation; seeking out a total of 13 convenience-sampled candidates of the following variety: 1 representative of a citywide umbrella organization of Business Improvement Area groups. 1 representative of a citywide arts promotion organization. 1 representative of an organization dedicated to the facilitation of social innovation, start-up incubation and social entrepreneurs networking. 1 international expert in tactical urbanism initiatives and participatory planning. 1 international expert in tactical urbanism with regard to vacant storefronts. 1 representative from a community organization from Corridor E, which promotes local small enterprise. 1 representative from a community organization from Corridor W, which promotes local small enterprise. 1 storefront (absentee) vacant property owner from Corridor E. 1 storefront (absentee) vacant property 
owner from Corridor W. 1 storefront business operator from Corridor E. 1 storefront business operator from Corridor W. 1 community-level arts organization in Corridor E. 1 community-level arts organization in Corridor W.

Due to the requirement of maintaining the confidentiality of local participants for securing Ethics approval for the research conducted with public stakeholders, and to mitigate the potential for political risks that would arise from the identification of specific participants in relation to discussion of real estate issues, collective neighbourhood activities and local business and property owner interactions, this research project does not identify the specific neighbourhoods, nor cross-streets, along Queen Street that were the focus of this study. For the necessities of comparison, one is referred to as Corridor $\mathrm{E}$ and the other Corridor W. 


\subsection{A REVIEW OF LITERATURE}

This literature review seeks to evaluate the existing research on the topic of tactical urbanism with regard to storefront vacancy and its interim use. This section commences with a look at the history of tactical urbanism as well as the causes of the phenomenon of storefront vacancies. This is then followed by a discovery of why vacant storefronts are considered a problem. Tactical urbanism as informal collaborative practice is then evaluated. The concept of urban vibrancy is defined and understood with regard to what may be considered as the missing, 'people' variable within more orthodox planning regimes. Next the importance and necessity for inclusive revitalization as a part of tactical urbanism initiatives is examined. A theoretical understanding of tactical planning finishes this review and the section closes with a quick conclusion of what is learned from all this source material, in order to direct the course of the primary research portion of this study.

\subsection{ORIGINS OF TACTICAL URBANISM—the Post-Soviet experimenters}

A great deal of experimental site intervention occurred in Germany and specifically in Berlin, after the fall of the Berlin Wall, with the preponderance of vacant sites in the former East Berlin after the fall of communism in 1989 (Overmeyer, 2007; Blumner, 2006). During this transitional period of regulatory vacuum, those with initiative and imagination were able to move to Berlin, live inexpensively and experiment with new ideas (Beekmans, 2009; Groth \& Corijn, 2005). Today, Berlin is considered the creative capital of Europe and this early influx of imaginative pioneers is recognized as contributing a great deal to this current status (Overmeyer, 2007; Blumner, 2006). 
illustration 1: Post Soviet regulatory vacuums created the conditions for pioneering interventions.

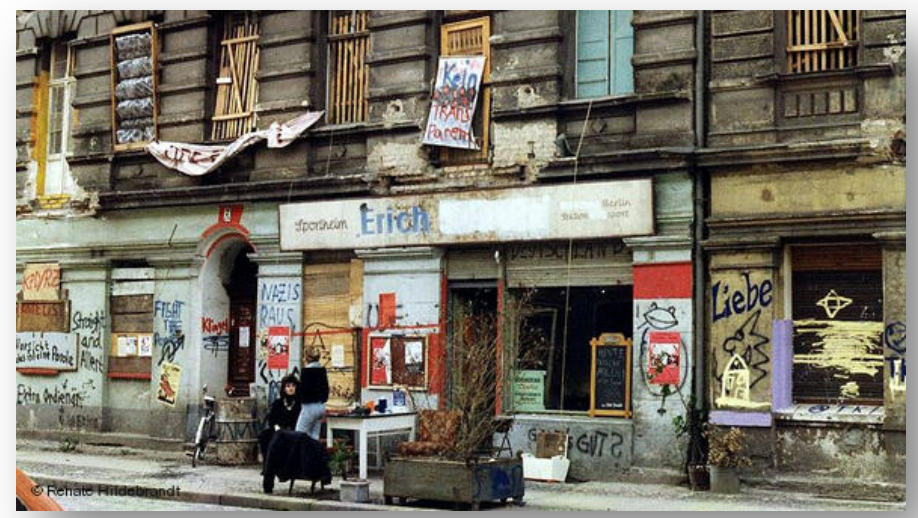

East Berlin's Mainzer Strasse in 1990 Source: Deutsche Welle

From 2001 to 2003 the European Union's $5^{\text {th }}$ Framework Programme funded Urban Catalyst, a program coordinating a team of ten partners throughout Amsterdam, Vienna, Helsinki, Naples and Berlin. This research project was organized from Berlin by what was later to become Studio Urban Catalyst (Overmeyer, 2007). Artistic, creative, new technology and experimental enterprises played a significant role in revitalizing areas of Berlin and were pioneers in the exploration of tactical urban planning initiatives. Studio Urban Catalyst, formed by Klaus Overmeyer at the conclusion of the Urban Catalyst project continues to operate in Berlin today, inspiring and partnering with other tactical urbanism initiatives throughout Europe.

As Overmeyer states, what is changing in urban centres throughout Europe, and Berlin specifically, is the shift towards higher levels of regulation, when compared with 20 years ago. This return to more bureaucratic land-use planning regimes, where previously there existed opportunities for unorthodox experimentation, has compelled some tactical 
urbanism initiatives to develop more organized means of informal intervention of temporary spaces (Beekmans, 2009). Studio Urban Catalyst is an example where a facilitating agency is able to engage with those seeking spaces, the owners of these spaces, as well as regulators to coordinate activities on a larger scale, has led to the proliferation of a functional tactical urbanism model in different European cities. Nicole Blumner speaks of the fact that in Germany, the term 'Zwischennutzung, or 'in between use'-the temporary activation of vacant land or buildings with no foreseeable development demand-“is an official planning term" (Blumner, 2006, p4), while the concept of interim use is as yet still not precisely defined in North American planning practice. Thus, at least in Germany, 'in between use' is able to be anticipated, involved and facilitated from a public policy perspective.

\subsection{THE CAUSES OF STOREFRONT VACANCIES}

The concepts of change and transition lie at the core of urban planning theory and practice. Marjana Johansson, quoting Mike Crang (2001, p190), reminds us that, cities are not stable entities, but rather "a becoming, through (the) circulation, combination and recombination of people and things" (Johansson, 2011, p394). Tanya Toft similarly quotes Gilles Deleuze \& Tom Conley (1992, p86) to again convey this notion of an 'urban becoming' — within an unfinished world, "shaped by the processes of events" (2011, p3). Tensions arise between the perspectives of the diversity of community stakeholders, as there are those indeed who perceive their cities as stable, while others conceive of the

temporally shifting nature of the urban environment in which they reside. Tactical 
urbanism speaks to the ability of those of the latter conception who seek to exercise agency, and be involved in the way in which their districts change.

It is thus important to note that change is endemic to the urban condition. As mentioned in the introduction with reference to Toronto's vibrant streets, healthy commercial corridors, even those not facing decline, may also contain vacant properties that may afford the opportunity for short-term incubation projects from tactical urbanism. In economic terms, these circumstances are referred to as the Frictional Vacancy Rate (Porter, 2008). In certain phases of transition, such as when property values (and thus property taxes) are increasing, tenant-seeking property owners may be willing to maintain vacancies while awaiting higher levels of rental income. In a related circumstance, property owners hoping to sell may merely hold commercial property with the hopes of profitable capital gains from a higher valued future sale- thus not truly intending to activate their spaces but leaving them vacant in the short to medium term.

This phenomenon may be discovered within certain commercial corridors within central Toronto that are in transition, inclusive of those to be investigated in this project, as related by neighbours or the local BIA. Although a corridor may be experiencing enhanced levels of activity and vibrancy, some storefronts may remain vacant with owners anticipating upward price pressures from higher levels of demand in the storefront retail real estate market. Within Toronto, even along relatively healthy streetscapes, such vacancies may leave porous gaps of inactivity. Tactical urbanism initiatives may be able to intervene even in these short-term gaps, creating opportunities for local stakeholders and stabilizing activity for the corridor. 
One contributing factor capable of unintentionally aggravating mere frictional vacancies to ones that endure for an extended period of time, are delays encountered in the land development process (Fletcher, 2012). Whether due to economic, financial or regulatory factors, storefront properties may be left vacant prior to demolition or renovations for some time during this turnaround of purpose (Earls, 2011). In this interim period, activity levels and thus overall street vibrancy may be negatively affected from the boarded-up properties remaining unavailable and uninviting (Jacobs, 1985).

Contributing factors to vacancy of more concern than mere frictional rates or the delaying of repurpose are what may be considered urban malignances in comparison. Several authors reference the term 'Shrinkage' or 'Shrinking Cities', (Earls, 2011; Groth \& Corijn, 2005; Havemann, 2007). Matthew Earls provides a cogent definition of such urban shrinkage, describing "widespread, sustained property abandonment and depopulation" (2011, p4) caused by out-migration from areas of a city that are less prosperous to those that are more economically healthy. Such commentary although applicable to many urban areas in North America, may not necessarily apply in such drastic form to otherwise robust cities where only specific neighbourhoods, corridors or blocks within the greater whole, may experience such shrinkage. This is the case in Toronto's urban core (McBride, 2010). Jason Fofrich (2004) speaks to this consideration by stating that many outer fringes of healthy urban systems are where most commercial activity has shifted to, leaving certain older neighbourhood commercial corridors bereft of their former vibrancy.

Such transitions are reflective of the endemic nature of urban change mentioned above. The opportunities open to tactical urbanism projects exist due to storefront 
vacancies that are caused by a multiplicity of transitory circumstances-whether relatively benign or malignant. Interestingly, as elaborated upon further in section 3.6 on inclusive urbanization, the involvement of local, tactical participants permits for a more nuanced understanding of these causes—whether benign or more malignant in nature-and the potential strategic actions that may be required in the longer term. Amongst causal factors, what may be considered one of the most malignant concerns in the shifting vacancies of neighbourhood commercial corridors is retail blight and its implications.

Although the concept of urban blight is of quite a wide and varied scope, with innumerably complex causal factors, this gravitational shift away from previously bustling urban districts referenced by Fofrich (2004), has been said to be a leading factor in the phenomenon of storefront retail blight (Berry, 1963). A succinct conceptualization of the causes of the dereliction storefront retail properties, specifically, was in fact articulated in Brian Berry's (1963) paper on commercial blight patterns in Chicago. Retail blight, he stated, could be classified into 4 different causal categories:

illustration 2: four forms of retail blight

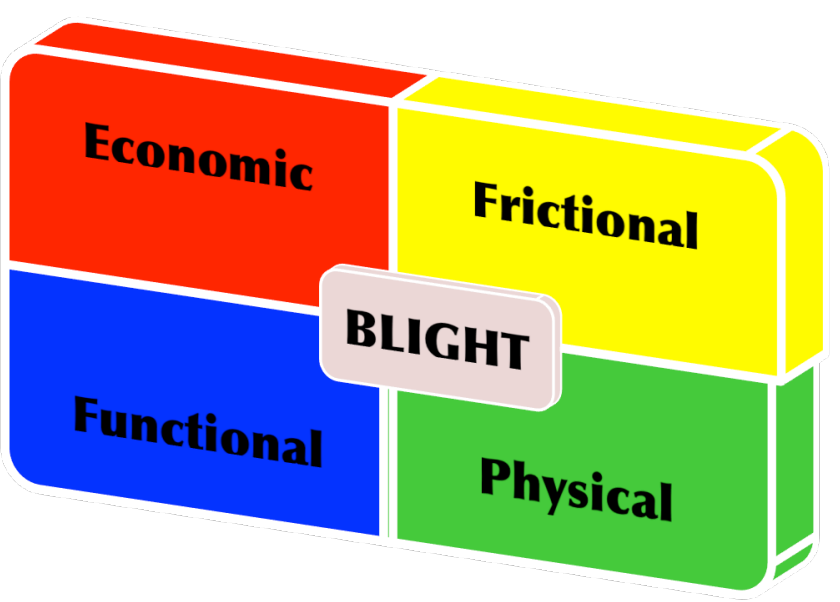


Economic Blight is the product of disequilibrium between the supply and demand of retail space. Frictional Blight refers to environmental issues, such as concerns with patron access or with non-complimentary neighbouring land use. Functional Blight is said to be due to technological obsolescence-an example being the need for larger floor areas for more efficient retail operations and the fact that this has caused many enterprises to move to less central locations, or conversely, the fact that urban consumers are more mobile than in previous decades (due to their access to private vehicles). Physical Blight as its name indicates is articulated as the degradation of older buildings, or districts, attributable simply to age, a lack of maintenance, or lax governmental inspections (Berry, 1963; Kelling \& Wilson, 1982).

These categories of retail blight, individually or in concert, are said to cause storefront vacancies on commercial corridors. Paul Whysall (2011) references 'poor retail management' as a variable Berry may have over-looked, although he states that perhaps it might be placed within the 'functional blight' category. He also speaks of the advent of ecommerce as another functional factor that has worked to diminish the vibrancy of retail corridors today (Whysall, 2011, p14). Discussion of such technological innovations however, perhaps fails to consider the power of social media in contemporary city life to engage citizens and along with the above-mentioned ease of mobility, allow for the potential of drawing resident activity back to commercial corridors-a fact this paper will revisit in later sections. 


\subsection{WHY VACANT STOREFRONTS ARE A PROBLEM}

George Kelling and James Q. Wilson's oft-referenced 1982 piece entitled 'Broken Windows,' effectively describes how vacancies and dereliction of property may become contagious. Untended property is said to invite vandalism, plunder and further neglect; when (the presence of) "one unrepaired broken window (signals) that no one cares...breaking more windows costs nothing" (Kelling \& Wilson, 1982, p3). The absence of a sense of ownership, or civic concern is said to invite a disregard for civic norms and mores. Kelling and Wilson state that those who wish to do damage or mischief are much less inhibited by urban environments that appear uncontrolled or uncontrollable. This notion is evoked today as the 'Broken Window Theory' in Sociological, Geographical and Urban Studies schools of thought.

The observation that atmospheres of neglect contribute to a diminished sense of public ownership of space arises throughout academic literature focused on the contagion of derelict properties. Richard Moe and Carter Wilkie in referencing the Broken Window Theory, quote the former mayor ${ }^{3}$ of San Antonio, Texas: "The way we feel about the place where we live governs our motivation to take care of it or neglect it" (Henry Cisternos as quoted in Moe \& Wilkie, 1997, p92).

This notion of a sense of ownership and community does not necessarily require residence alone, but occurs in the sense of ownership and pride of community expressed by commercial networks as well (Fofrich, 2004). Moe \& Wilkie (1997) note that successfully confronting the threat of urban decline requires the attention of both residents

\footnotetext{
${ }^{3}$ Henry Cisternos was later to be appointed the Secretary of Housing and Urban Development in the Clinton Administration.
} 
and visitors - with the ideal of preservation referring to more than built form, but also the communities and the people who exemplify the fact that an area is worth spending time in.

A fundamental aspect of deteriorating conditions on commercial corridors is a decline in the number of people present on the sidewalks. Whether as patrons or merely passing pedestrians, their absence contributes to "fears of public safety," (Moe \& Wilkin, 1997, p84) due to a weakening sense of social control and vigilance (Kelling \& Wilson, 1982). Although these fears may merely begin as perceptions, they gradually become selffulfilling as more and more people avoid an area, move from the area, or "dream of getting out" while withdrawing from the public realm (Jane Jacobs quoted in Moe \& Wilkin, 1997, p84).

Well known planning theorist and critic Allan Jacobs (1985), writing in his book Great Streets, speaks to elements of vibrant commercial corridors-streets that welcome visitors and residents rather than drive them away. Such streets, Jacobs contends, invite levels of passive, yet still participatory, engagement (Jacobs, 1985, p272)—engagement which storefront vacancies diminish. With boarded up windows and ill-maintained environs, individual storefronts begin to lose what Jacobs terms 'Transparency', or the quality whereby "the public realm of the street and the less public, often private realm of the property and building meet. . (a passersby no longer) senses an invitation to view or know, if only in the mind, what is behind the street wall" (Jacobs, 1985, p285).

Urban theorist Kevin Lynch, in his popular conceptualization of urban imageability, speaks likewise from the perspective of the participatory engagement of city 
dwellers. When defining the notion of legibility he describes how vibrant pathways, or corridors "invite the eye and the ear to greater attention and participation," such spaces, he states, "could be apprehended over time as a pattern of high continuity with many distinctive parts clearly interconnected (1960, pg10). Derelict, shuttered spaces interspersed amongst activated storefronts, for this reason results in what in a Lynchian sense, may be termed 'diminished legibility' for the passerby.

These nuanced, almost intuitive, impressions which streets are able to insinuate are why with storefront vacancies, erstwhile engaging commercial corridors may draw fewer and fewer people. Allan Jacobs explains, "Void of human activity, streets soon cry out for people, they need people at the same time as they are for them, they are activated by them at the same time as they contribute to making a community for them $(1985, \mathrm{p} 303)$.

Indeed, people are said to be the key to reversing trends of decline although people have often in the past, been the subject most often absent from the focus of official, government-led revitalization strategies. Allan Jacobs conveys this perspective in stating that planning interventions often involve drastic actions without a clear understanding of local realities (Jacobs, 1985). It is through collaborative engagement and outreach that these local realties may be shared and understood for effective planning interventions. This perspective of people being a 'missing variable' is discussed further in section 3.5. As mentioned earlier, Toronto does not suffer from the extremes of urban retail corridor decay as that found in many urban centres in the United States (McBride, 2010). Nevertheless, the observations of Jacobs (1985) and Lynch (1960) referenced above, still apply to the Toronto experience, where individual blocks, commercial corridors, or 
districts may experience higher rates of storefront retail vacancies than that found in the rest of the city. From another perspective, the existence of storefront vacancies-however short-term—-may influence the vitality of neighbouring storefronts, and lead to disruptions in human activity, affecting the 'marginal level' of vibrancy along the whole corridor.

Within the Toronto context, the current highly formalized method of participation in the planning process involves what Gerald Hodge (1991) in his work Planning for Canadian Communities, defines as a three phase process-plan making, plan implementation and plan clarification. Within these phases, the public is provided incidental opportunities to provide input—within plan making and at the stage of clarification. Rarely if ever is the public able to actively initiate changes absent preemptive oversight by formalized authorities or experts, in accordance with set protocol. Hodges mentions how in most traditionally developed Canadian cities, planning has been the purview of a relatively few people, and that "it is actually possible to identify who in those cities planned this or that element—and they usually had some official capacity" (Hodges, 1991, p333). The role of planners however has been in a state of transition for several decades, with more and more stakeholders seeking the expertise planners provide in guiding their ability to involve themselves the formal process of city-building.

The exclusive manner of this process and the limited possibilities to become engaged and effect change is reflected in the Province of Ontario's 'Citizen's Guide to Planning'. This ten-part guide informs stakeholders within the community, and advises them on how they may contribute to the planning process in Toronto. Each of the ten parts delineate specific aspects of the formalized structure of municipal planning regimes 
in Ontario. The guide makes reference to such legislative tools as the Ontario Planning Act, Municipal Zoning By-laws as well as Municipal Permits. In addition, formal avenues of recourse are mentioned which exist for members of the public who wish to express opposition to local planning directions-by way of mediative panels, committees and quasi-judicial tribunals (Ontario Ministry of Municipal Affairs and Housing, no date). Such formalized, methodical means of engagement however contrast with tactical urbanism's more informal, 'bottom-up' quality.

\subsection{THE OPEN-SOURCE NATURE OF TACTICAL URBANISM}

Tactical urbanism is the anti-thesis of formalized planning. It has been referred to as "open-sourced" (Sassen, 2011). In the same manner that open-source software code is available to anyone who wishes to contribute, alter or customize a program, tactical urbanism begins with the initiative of public participants and not from the following of officially charted protocol. It is a bottom-up process rather than one that is sanctioned from above.

Chiara Camponeschi (2010) a champion of collaborative outreach with community-based, active citizenship endeavours; views tactical initiatives as avenues for city-dwellers to be the initiators of action by contributing perspectives, expertise and solutions. These participants are not merely awaiting the consideration of policy makers who perceive them as municipal elements to be pandered to. Based on her idea of allowing such individuals to become actively involved in the betterment of their communities via interactive, deliberate and considerate ways, Camponeschi elaborates 
her concept of 'Place-Based Creative Problem Solving' as "the leveraging of the imagination, and inventiveness of citizens, experts, and activists in collaborative efforts that make cities more inclusive, innovative and interactive" (2010, p10)—a description which would function as effectively as a definition for tactical urbanism.

Grassroots initiatives at combatting commercial property dereliction through the temporary tenancy of vacant storefronts are referred to as "informal revitalization" (Corijn, 2005, p3) or "transformative interventions" (Johansson, 2011, p393). 'Temporary-', 'Ephemeral-', '-Transitory-', 'Provisional-', 'DIY-', 'Guerilla-', 'Ad-hoc-', 'Open-source-' and 'Tactical $-' \ldots$-Urbanism are but some of the numerous epithets which reference locally-led efforts at "empowering local residents to take ownership over their environment" (Camponeschi, 2010, p5).

illustration 3: 'urban acupuncture'

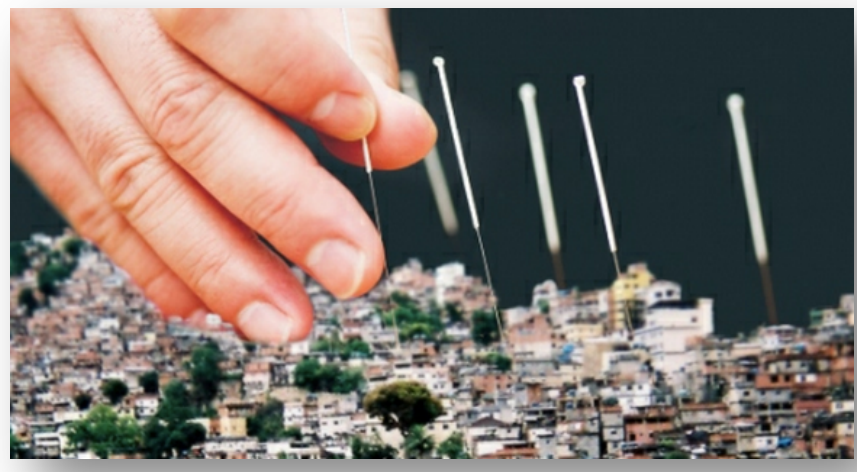

One of many terms to describe 'tactical urbanism.' Source: www.mozardien.com

The German organization Urban Catalyst, define three requirements for a Tactical Urbanism project to fit this concept:

1) "people other than the real estate owner perform activities on the site" 
2) "the owner receives no, or no relevant, financial income for this use"

3) "The use is time-limited"

(Studio Urban Catalyst, as quoted in: Earls, 2001, p6 and Hentila, 2003, p3)

Use of property not in keeping with its original or planned purpose is also mentioned as a key characteristic (Earls 2011), with Groth \& Corijin specifically highlighting how such "transitional re-appropriations that are assumed by civil or 'informal' actors coming from outside the official, institutionalized domain of urban planning and urban politics" (2005, p 506), allow for more organic urban planning endeavours. Informal actors from the creative community, enterprising startups, hobbyists or cottage industries, all considered "urban pioneers," (Alter, 2009, p1) may create "collaborative initiatives" (Camponeschi², 2012, p1) which "benefit the community by reinvesting in the local economy and supporting other local institutions" (Fofrich, 2004, p20). Although many scholars (Alter, 2009; Kahn et al., 2009; Fofrich, 2004) regard the artistic community as the most obvious innovative urban colonizers of vacant properties, there are those (Earls, 2011; Graham, 2012) who also describe a more diverse pool of potential urban pioneers - "from gardening, leisure and sport, to social experiments and services, youth and pop culture, art and music, nightlife, trade, industry, invention, entrepreneurship, and start-up companies"—as those who can contribute as initiators towards the same end (Earls, 2011, p5).

Such collaborative endeavours necessarily involve property owners (Blumner, 2006; Evans, 2009; Earls, 2011). The tactical activation of vacant storefronts provides an 
opportunity to reduce expenses associated with maintaining and securing vacant property. Savings arise from removing the necessity for preventative action such as "mothballing, fencing, and policing... to curtail damage...by natural forces... as well as trespassers" (Earls, 2011, p4). Through the continued occupation of property and the utilization of infrastructure such as plumbing and heating equipment, maintenance occurs in conjunction with a surveillance presence-contributing to benefits enjoyed by the property owner as well as the neighbouring area (Earls, 2011). Vigilance is however most inexpensive and ubiquitous when due to the presence of engaged, concerned citizens, or as Jane Jacobs (1961) referred to them, 'eyes on the street'—elements found in abundance along corridors or districts considered 'vibrant'.

\subsection{URBAN VIBRANCY: The 'People' Variable}

Enhancing street vibrancy is considered a primary goal of tactical urbanism endeavors. Urban vibrancy has been qualitatively defined as the "attracting (of) people, activities and value to a place and increasing the desire and the economic opportunity to thrive in a place" (ArtPlace, 2011, p1); the creation of areas of identity and pride for the community (Fofrich, 2004); spaces which allow for staging and consumption (Johansson, 2011). Vibrancy is thus created when the public is able to come together for a variety of activities and functions in specific places.

Some scholars (e.g. Mean \& Tims, 2005; Earls, 2011; Jacobs, 1985; Fofrich 2004; Alter, 2009) point to orthodox, more top-down, urban planning revitalization initiatives 
(although seeking the same end as grass-roots endeavors) as lacking an important focuspeople. "A new town square could be carefully, beautifully designed, but there was no guarantee that people would come and use it. People have a wide variety of motivations, needs and resources that shape their personal capacity and desire to use...space." Indeed, "public space is co-produced through the active involvement of the user" (Mean \& Tims, 2005, p10)

Such active involvement of people (or 'users') is needed not only in the planning and development of space but also in the continued appreciation of it. The concept of the 'experience economy', within an intra-urban context, speaks to drawing people back to districts, allowing them to reacquaint themselves to parts of a city with which they may have become unfamiliar.

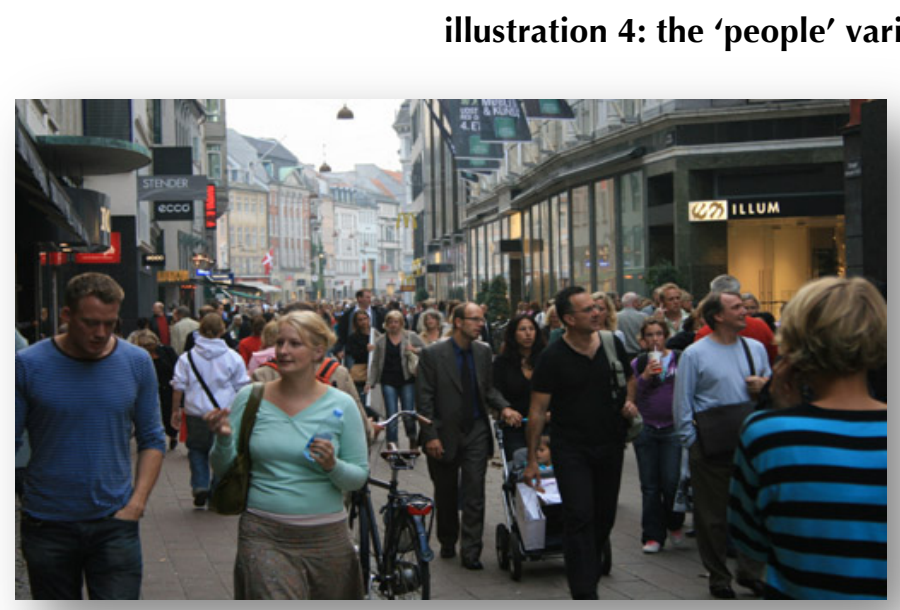

Source: www.streetsblog.org

Matthew Earls echoes such sentiments, observing how tactical interventions act to enhance the visibility of individual storefronts or the commercial corridors in which they 
are located, thus, "bringing areas back into the social consciousness of a city (2011, p13). Marjana Johansson similarly, while reflecting on the importance of urban festivals, touches upon an aspect of ephemeral urban experience that may apply to storefront tactical interventions in much the same manner-as they compel city dwellers to become once more "acquainted with those parts of the city that they do not normally visit" (2011, p400). Indeed, tactical urbanism may be considered from one perspective as an extended festival. Urban theorists use the term "Experience Economy" (Fofrich, 2004, p42; Johansson, 2011, p393; Graham, 2012, p27) in reference to how cities, as a whole, may compete with other cities to draw visitors seeking to invest their time and money for specific activities.

Within larger urban areas, such as Toronto, this competition may be applied to distinctive districts, neighbourhoods or retail corridors able to offer what is termed 'placebound" "activities, events and services, attractive places and diverse social spaces, which make visitors and residents feel inspired, involved and connected to the place" (A.Lorentzen, quoted in Johansson 2011, p394). Attracting participants to such 'experience'-based activities is mentioned as a key element of success for tactical urbanism initiatives (Fofrich, 2004; Moe \& Wilkin, 1997; Alter, 2009), as well as the enhancement of urban vibrancy.

Local economic spillover benefits from vibrant commercial corridors, which arise from drawing patrons from throughout a metropolitan area, are the objective of community-led revitalization (Fofrich, 2004). Neighbourhoods are able to function "as centers for the arts, entertainment, face-to-face trading, and the creation of specialized 
artisanal goods and services," (Fofrich, 2004, p42) "a site of use, symbolism and experience" (Johansson, 2011, p393). The mere engagement of city dwellers at times contributes a great deal to the redefinition of selected urban areas. The nurturing of such engagement is altering the role of city administration, in the quest for inclusive revitalization.

\subsection{INCLUSIVE REVITALIZATION}

Moreso recently than in the past, urban dwellers are able to involve themselves in the evolution of their cities. Nicole Blumner refers to this as the ability to "take a place at the decision-making table along with the traditional big players of government and private investment" (2006, p4). Urban revitalization is neither a new concept nor a new aspect of the urban experience, but its activating forces are being challenged. This is alluded to by Chiara Camponeschi in her depiction of 'Place-based Creative Problem Solving', and echoed in Stacey Sutton's definition of participatory neighborhood revitalization as "community-led visioning and planning processes that seek to improve social conditions, physical infrastructure, economic opportunities, civic capacity, and local organizational structure" (2010, p353). The notion of inclusive revitalization references those involved in a process of planning intervention: the actors and the level of collaborative involvement possible for the many stakeholders who are affected and concerned with stabilizing, reversing, or arresting the spread of property vacancies in neighbourhood commercial corridors.

The advent of tactical urbanism calls for planners to perform as facilitators, while 
providing professional expertise, rather than solely as regulators. By bringing disparate stakeholders together, planners may mediate towards the best scenarios for temporary interventions, with the longer term objective of local area vibrancy (Graham, 2012; Whysall, 2011)_inviting locals to "take a greater role in the shaping of their environment" (Earls, 2011, p23). Paul Whysall evokes the "local coordination of key actors," participating together in a "concerted attack" on the dereliction of commercial properties. These actors include "retailers, landlords and property owners, urban planners" (2011, p15), "urban authorities, private promoters, parts of civil society," (Groth \& Corijn, 2005, p504) "artists (and) concerned residents" (Alter, 2009, p2).

With such a plurality of voices seeking to be heard, urban planners and municipal administrators are challenged to not merely reflect those special interest groups who "already cultivate an active interest in urbanism, but include as well the vast majority of city-dwellers who may continue to find the local planning process "too nebulous or out of their reach" (Camponeschi ${ }^{2}, 2012$, p12). The thesis of Chiara Camponeschi's research paper entitled 'The Enabling City', succinctly conveys the view that "cities will need to facilitate a transition to 'enabling' frameworks for enhanced participation, social experimentation and responsive governance." (2012, p10)

This idealized conception of local planning engagement, however, is challenged. There are those who view the involvement of so many distinctive players in the enterprise of tactical urbanism, and local area commercial corridor revitalization, as a motley configuration of conflicting interests. Groth \& Corijin observe that the multiplicity of "stakeholders' prerogatives (impact) on the further existence of the (vacant) spaces and 
outline the nature of alternative claims and visions of (future) development" (2005, p506). Alexandra Alter (2009) introduces the concern common with all city-building interventions - the conflict between who may benefit from a change and who may be disadvantaged.

Artists previously involved with local area planning interventions "have had the effect of gentrifying neighborhoods that were (already) working for the existing communities," (Dana Cuff ${ }^{4}$ —as quoted in Alter, 2009, p5). Indeed, in the same paper, Alter quotes artists themselves who lament having participated in the process of inclusive revitalization of commercial corridors, as they now find themselves unable to afford to live and work in the newly trendy streets, "now dense with cafes, wine bars and art galleries" (2009, p4). This is apparent as well when Stacey Sutton speaks of purportedly 'inclusive' planning interventions that "overwhelmingly benefit non-local interests, often with adverse effects for neighborhood incumbents in the longer term (2010, p354). Actors external to a neighbourhood are thus cynically considered not endeavoring for a local community's best interest-the revitalization is 'inclusive' only in name, but not in practice.

Further cynicism is leveled which reflects a tone of 'urban-Darwinism'. "Strong neighbourhoods maintain themselves, weaker ones demand intervention" (Moe \& Wilkin, 1997, p53). Such opinions question whether fleeting glimpses of 'vibrancy', would enhance or distort corridor resiliency. It is claimed that true revitalization would only arise after investment from permanent, local, stakeholders_only then may commerce, new

\footnotetext{
${ }^{4}$ Cuff is an architecture professor at UCLA as well as founder of cityLAB, an urban-design think-tank.
} 
jobs, and a growing tax base (develop) (Moe \& Wilkin, 1997). Groth \& Corijin raise the question of whether focusing so much on the temporary and inclusive, results in "piecemeal planning procedures (to the) detriment of comprehensive, multifunctional master plans" (2005, p504).

Proponents of inclusive revitalization however, point out that creating a critical mass of activity within these neighbourhoods may in fact foster foundational catalysts to change. Jason Fofrich states that by "providing unique environments ... (and) harnessing this ability of strong experiential places, areas in the central city that have been abandoned can create a strong attracting force" $(2004$, p55) to city dwellers. In the interim, local initiatives may result in the production of stabilizing improvements to an urban environment in a variety of environmentally, socially, economically, and culturally enriching ways; while at the same time inviting local stakeholder contribution and involvement with the change occurring in their community.

Matthew Earls states that in fact the tactical urbanism opportunities afforded by inclusive revitalization may be "useful in buying time for policy makers and planners in the short and medium terms, while more significant, underlying issues are addressed" (Earls, 2011, p24)—thus allowing for an ongoing dialogue on how to guide local community change, both at a local level as well as a municipal government level.

A co-panelist on a 2011 seminar on Tactical Urbanism, where Chiara Camponeschi was invited to participate, stated that such projects are in fact reactions to governmental inertia that stifles innovation (Riano, 2011). Chiara herself concurred, explaining that temporary urbanism demands more flexibility from governance models (Camponeschi ${ }^{4}$, 
2011). Short-term action, she claims, is capable of leading to long-term institutional change.

Municipal administrations today, Nicole Blumner states, are confronting shifting roles when reconciling the opposing viewpoints above—- "from a regulating role to an activating one" (2006, p4). This represents, as well, a shift in the municipal power dynamic with citizens now afforded the opportunity to play a more active role in the development of their urban areas—alongside "the traditional big players of government and private investment" (2006, p4).

Discussions of the ontology of an urban 'becoming' and its contrary position, the ontology of an urban 'being' -the perspective of stability and consistency, in conjunction with the notion of a changing municipal power dynamic, necessarily lead to the theoretic foundation of tactical urbanism. With a discussion of planning tactics, there is always a parallel evaluation of planning strategies.

\subsection{A THEORETICAL BASIS—From Strategic Planning to Tactical Planning}

Those (Arlt, 2004; Groth \& Corijn 2005; Temel, 2004; Toft, 2011; Teder, 2011;

Graham, 2012) involved in the discourse on inclusive planning endeavours, distinguish between the process of tactical urbanism in comparison to more formal, bureaucratic efforts. This contrast, juxtaposes the vertical power dynamic found in traditionally structured, government-led, 'strategic' masterplanning, with today's more innovative styles which display more versatile, horizontal power dynamics, and 'tactical', collaborative organizational models. 
Peter Arlt (2004) evokes the military origins of this conceptual divergence. Strategists,

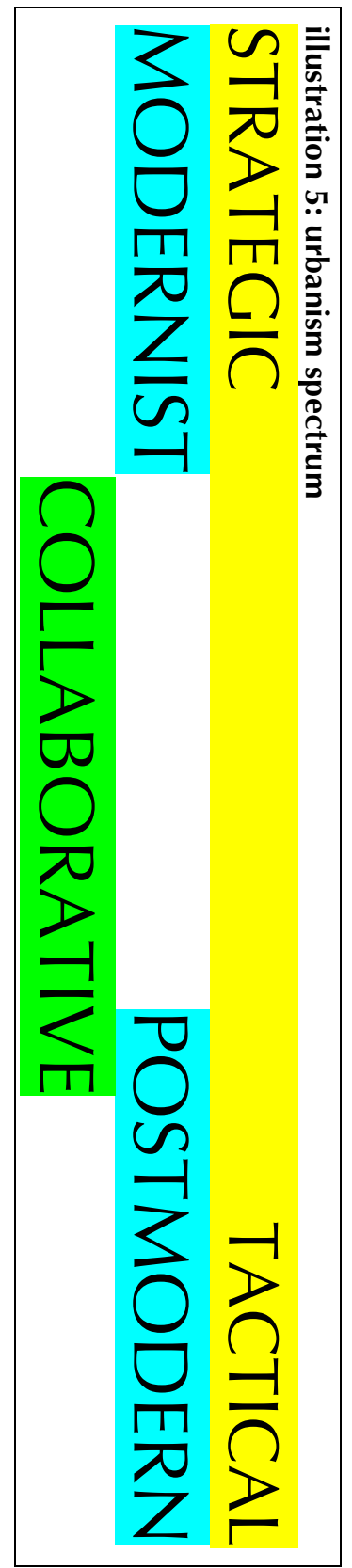
he states, possess sufficient wealth and power to achieve their objectives without paying heed to external conditions, as they indeed may augment such variables at will. This references the fiscal and legal capacities of municipal administrations to effect change when and where they please at the local level. Tacticians conversely, due to a lack of sufficient wealth or influence, are only able to achieve their objectives through adjusting themselves to their environment and collaborating with other stakeholders. A tactical urbanist similarly, must conform to the (most significantly, legal) environment created by municipal administrations.

Groth \& Corijn (2005) emphasize too, the environmentally synergistic nature of tactical collaboration, claiming it capable of creating local programming which reflects an increased awareness of 'particularities' which traditional planning regimes' more authoritarian and scientific abstraction of a city's life may be incapable of distinguishing. The tactical stance is also described as more "everyday urbanism" by Robert Temel (2004), where the goal—not the adversary—is heterogeneity. If strategists are normative (i.e. compelled to follow standards, or norms) in style, he states, tacticians are specific —-reacting to existing situations and attempting to reinforce their qualities" (Temel, 2004, p56). 
Everyday Urbanism is indeed a concept that arises frequently in the literature in discussing ideals of community-based, participatory planning. Harrison Fraker writes of how it celebrates the "everyday space of public activity" and how everyday urbanism considers the city a "social product" (Fraker, 2007, p62 as quoted in Graham, 2012 p24). Everyday Urbanists are in fact Tactical Urbanists, as they seek out flexibility of land use programming and planning and appreciate active citizen involvement in the planning process (Graham, 2012, p25).

The foundational basis of the everyday urbanism philosophy leads to a political analysis behind the distinction between tactical and strategic urbanism. Michel De Certeau (1984) who conceives of the master-planned city with planners and policymakers as producers working from a position of power while city dwellers, lacking such power, are merely classified 'users of the city'. In such a circumstance, he sees an explicit understanding that master-planning is conducted by those in positions of power, while those who lack power react through tactical organizing to effect change and alter their urban experience.

De Certeau's notion of power imbalances is once more echoed by Henri Lefebvre (1991) who analyzes the production of urban space with the contrasting concepts of representations of space and representational space. The former is described as constructed and imposed by those in authority, while the latter is a mediated response by those who use the city. Tanya Toft references Lefebvre $(1991$, p33) in drawing this framework towards ideas of tactical urban initiatives, noting that, "If rational planning falls into the category of ordered representations of space, temporary use of urban 
environments falls into the representational space (signifying) the 'underground side of life'" (2011, p6).

Strategic and Tactical Urbanism may be said to exist at two ends of a spectrum; today shifting more towards the tactical, collaborative style of urban planning which strives engage a diversity stakeholders and understand specific conditions. Higher levels of respect and consideration are now anticipated and greater agency exercised by city dwellers with regard to urban development initiatives. With increasingly diverse citizen needs, the level of citizen involvement and importantly, heightened desire to affect local change, a new attitude to municipal governance is being practiced. And the abovetheorized, traditional power imbalances are shifting.

Described as 'open-source urbanism' (Sassen, 2011) or 'bottom-up planning,' what is reflected today, is how newer synergistic platforms are being created to more accurately diagnose and react to local issues such as urban shrinkage, property vacancies, and crime, amongst others, by inviting a multiplicity of contributing perspectives (Groth\& Corijn, 2005). Tanya Toft speaks of such "empowered urban agency as a productive force", with tactical urbanism initiatives being "productive public sociability" $(2011$, p6).

This productive empowerment however, is not necessarily labeled as antagonistic towards traditional forms of planning. Chiara Camponeshi, offering her views directly to the researcher for this paper-echoing the opinion of Matthew Earls (2011, p24) in Section 3.5, above-points out how temporary urbanism initiatives are able to function as indicators—articulating neighbourhood-level problems and thus, in being encouraged and facilitated, are able to help define further underlying needs to municipal policymakers. 
Tactical urbanism is not a cure-all. It does not solve, especially long-term, systemic issues and is not meant to behave as a permanent resolution. It is however, able to function as a community stabilizer in the interim. Municipal governments remain vital sources of major structural, strategic change, and ought to be engaged with, and lobbied, to develop communication structures with local community stakeholders-such as those involved in initiatives to enhance their local commercial corridors.

While Chiara Camponeshi assesses the innovations occurring in collaborative governance models, active, engaged citizenship and how this is altering the relationship between city dwellers and municipal policymakers, Marcus Westbury, an international expert in tactical urbanism with regard to vacant storefronts, sees his primary objective as shifting to the facilitation of who he terms 'initiativists' - those who lack not for ideas and will but opportunities and resources to implement them. In a conversation directly with the author, he stated how he creates chances for both success and failure for his initiativists to experiment and develop erstwhile economically unviable projects through the lowering of barriers to entry. Consequently, both of these innovators' efforts can be said to strive for vibrant urban places. Integral to the success of tactical urbanism is a dualistic focus evoking both of these ideals.

\subsection{CONCLUSION OF REVIEW}

Although the idea of tactical urbanism, within the context of storefront vacancy interventions, are still relatively uncommon, there was still sufficient literature available to discovery quite a number of interesting aspects of this planning tool to aid our research 
direction. What influences the existence of vacant storefront is a variety of complex, interconnected attributes of the average commercial corridor. From the benign frictional rate of vacancy which would result in there always existing some minimal level of available intervention sites, to the four, more malignant forms of retail blight which Brian Berry's (1963) research illuminates; within the context of Toronto it is key to develop an understanding of whether vacancies represent further underlying circumstances in the neighbouring area. Seeking out appropriate local informants is key, for this reason. As Allan Jacobs (1985) notes, planners have often misdiagnosed causal circumstances, and have proceeded with more strategic interventions, to the detriment of local citizens. Equally, this review of literature grants an understanding of specific arguments as to why vacancies may be a concern, and provides both this research project, as well as any future tactical initiatives, the ability to engage with local stakeholders and help communicate both the potential problems as well as available opportunities that may arise from the existence or proliferation of vacant storefronts.

Most information available does not provide much detail from long term experience whether beneficial or otherwise. What is yet required is a longer-term assessment of the effects of existing tactical interventions of this variety. Qualitative and perhaps more importantly, quantitative analyses of neighbourhood vibrancy, economic stability and gentrification concerns would help enrich the discourse and create answers for the questions raised. Is the concept of 'marginal vibrancy' in any way quantifiable? How may the benefits of implementing tactical interventions be measured? 
Previous experience from Toronto, for obvious reasons, is not represented in the literature (nor from Canada for that matter). This establishes the need for this current investigation. It is somewhat disheartening to note that the Vacant Commercial (property) Tax Relief program in Toronto still applies to storefront property. Political action and awareness is present however, so it may be that were more Torontonian stakeholders concerned about the unfortunate reality that the maintenance of vacancies is subsidized by the city, perhaps more will be done to alter the current legislation. From this review of literature we will proceed to a review of practice-an in depth examination of how a specific tactical urbanism initiative functions. 


\subsection{REVIEW OF PRACTICE}

\subsection{NEWCASTLE-AUSTRALIA'S DETROIT?}

illustration 6: Newcastle's main 'Hunter Street' strip, prior to Renew Newcastle's intervention.

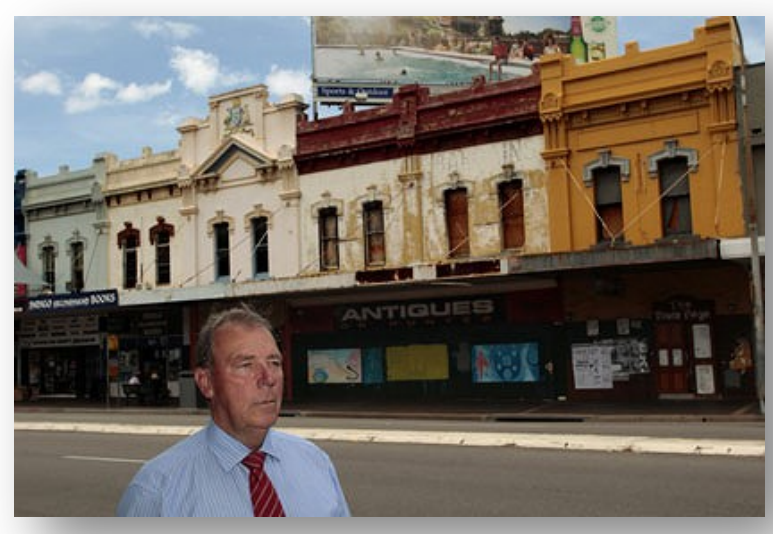

Source: Jonathan Carol

By the late 2000s, the city of Newcastle, located in the Australian state of New

South Wales, was an industrial metropolis in decline. With a loss of manufacturing investment, compounded by decades of suburbanization, its Central Business District had experienced continued out-migration and no longer attracted the commercial activity it once had. In 2008, 150 empty retail and commercial buildings were to be found in its main Hunter Street mall and its periphery (No Author, October 28, 2011). All the hallmarks were evident, of the 'urban shrinkage,' and Brian Berry's (1963) concept of functional blight described earlier in this paper, in section 2.1.

It appeared that many boarded-up storefronts were "worth more as losses, write offs and deductions than as going concerns...the potential rents so low, that few (property owners) bothered renting them (out) (Westbury, 2009, p3). Additionally, with real estate commissions negligible, commercial leases prohibitively long by default, and property owners being required to fulfill expensive government obligations in order to lease out their properties, there did not appear to be a solution to the growing blight, 
notwithstanding the presence of enterprising locals willing and able to explore experimental initiatives. With the municipal government establishing strategic plans that never quite stimulated activity on the newly beautified streets, more tactical initiatives were called for. Marcus Westbury became aware of experimental interventions in Western Europe, which were gaining publicity worldwide for challenging regulatory frameworks and creating vibrant urban centres of renewal through citizen-led action.

\subsection{MARCUS WESTBURY'S "RENEW NEWCASTLE"}

In 2008, Marcus Westbury was lamenting the sad state of Newcastle-the city of his childhood. Involved in a variety of ways in the arts community, he contemplated whether it would be possible for him to find enough interest in the local creative community to launch a tactical intervention initiative. Beginning a discussion on Facebook, he was surprised to receive interest from hundreds of Novocastrians. Today there are over 3400 users actively following and supporting Renew Newcastle's activities. "They are almost all Novocastrians and a great diaspora of former Novocastrians from New York to New Zealand. You can work with and sell to all of those people (online) from Newcastle now" (Westbury, 2009, p6). 
illustration 7: Renew Newcastle in the process of revitalizing empty storefronts.

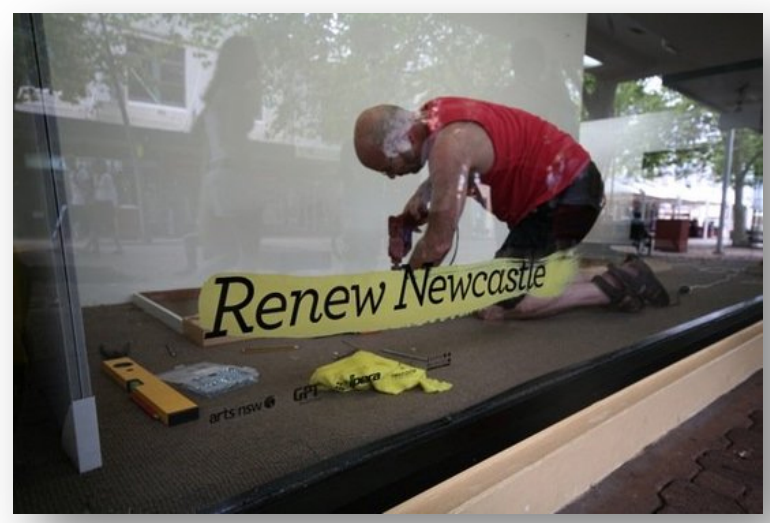

Source: Renew Newcastle

Renew Newcastle was founded soon afterward, and had established 40 creative enterprises, in 25 formerly empty storefronts, by the end of its first year. It was quickly recognized as a catalyst in drawing commercial investment back to the formerly desolate central core of Newcastle. Property owners, business groups, the media and politicians all lauded the efforts of Renew Newcastle in successfully reestablishing street life and economic activity to areas that for years had been in decline and experiencing dilapidation.

Westbury refers to Renew Newcastle as "a low-cost, low-budget do-it-yourself urban renewal scheme" (2009, p1). He speaks of the power of "initiative, experimentation, entrepreneurship and innovation" (2009, p5), which is harnessed in his scheme. Money is "a poor substitute for passion" (2009, p5), he states_noting that grassroots revitalization does not require large sources of funding from governments nor corporate groups to achieve success. Westbury observes that "cities look very different from the small scale street level than they do from the models of politicians, planners, dictators and economists-Renew Newcastle is an exercise in thinking small" $(2009, \mathrm{p} 7)$. 
Every vacant property possesses the "potential to launch creative projects, businesses and initiatives and to incubate new ideas" (Westbury $\left.{ }^{z}, 2012\right)$. The goal of Renew Newcastle is to reduce or eliminate specific barriers to entry faced by community members with ideas, visions and initiative but without the capital to be able to attempt new enterprises or the ability to risk failure.

\subsection{HOW IT WORKS ...}

\subsubsection{Intermediary Space Broker}

Renew Newcastle is a not-for-profit company with a board of directors representative of the arts, business, legal and accounting communities. Its intermediary role implies that complexities such as public and property liability insurance, utility accounts, risk management as well as any communication or negotiation with skeptical property owners are all under the purview of an umbrella agency. With individual occupants not required to involve themselves with each of the above concerns, Renew Newcastle is able to leverage a continually growing level of goodwill, credibility and brand recognition within the greater community and city to mitigate risks and reduce costs, while gaining access to more and more vacant space, as well as engaging an increasing number of stakeholders.

Renew Newcastle plays the role of an intermediary space broker. Through the versatility of rolling 30-day licensing arrangements between property owners and Renew Newcastle, they are always able to guarantee property owners the return of their 
properties for any original intended purpose in less than 30 days time. This would mitigate any opportunity costs that participating property owners could face.

\subsubsection{Licenses not Leases}

The benefit of licensing over leasing is multi-fold. Licensing does not incur property, nor income, taxation along with any tenancy law obligations on the part of the property owner. Leases, easements and licenses experience differential treatment under law, with the first two benefiting from statute law and the latter only having common law provisions. Licenses therefore are not as rigorous in their contractual obligations. Whereas a lease and easement provides the occupier of property an interest in the land, a license does not. A license acts merely to grant the privilege of having access or use of a property, without which such entry or use could be construed as trespass. Licensees are granted access to the property free of charge or with merely a nominal fee. Tenancy statute protection—regarding eviction, interest in the property and access—is dependent upon such financial transactions, due to the fact that with the payment of appreciable rental fees, an occupier is considered an authorized guest and not a leasee. (Duhaime, 2009) Intriguingly, legislation in Ontario guarantees the same differential treatment between Lease and License agreements—-this is discussed further in Section 7.0.

Benefits to the property owners accrue not only from having their properties occupied and protected from vandalism and disuse. Renew Newcastle takes it upon itself to act as quasi-property managers—repairing damaged windows, applying a fresh coat of paint, cleaning and tidying the area and removing graffiti (Westbury, 2009). Properties up 
for sale or rent are thus able to show in a much better state of repair while under the stewardship of Renew Newcastle than while boarded up and abandoned.

Renew Newcastle strives to select prospective occupying participants for the vacant storefronts carefully, asking for a demonstrated history of initiative and strong work ethic. They then determine the prospective project's suitability to the intended environment. Simple resale of wholesale merchandise is not permitted and complementarity of function/non-competition with neighbouring market-rent paying enterprises is stressed. The focus is always on the incubation of start-ups-those who innovate and create, bringing something unique and attractive to the area. With many more candidates than available spaces, a high standard of selection has been maintained, which works to secure Renew Newcastle's reputation. Although launched on a shoestring budget, Renew Newcastle today boasts funding contributions as well as political support from municipal and state government departments for revitalization and artistic programming.

\subsection{HOW RENEW NEWCASTLE EVALUATES SUCCESS}

The concept of success is relative for Renew Newcastle. From the onset Marcus sought to embrace 'failure' which implied that although some interventions have indeed developed into successful enterprises-occasionally in the very properties where they began—thus converting into full rent paying tenants and leaving the Renew program, many have not. The experience these unsuccessful ventures gain from their time as space activators may evolve, however, into further, more refined concepts or altered creative plans - which may then again be tested in Renew created spaces. Lessening the fear of 
failure, while providing an educational opportunity for those attempting new concepts is in this way, one aspect of the success of Renew Newcastle.

Marcus Westbury realized his initiative had achieved a distinctive form of success when developers and property management firms began themselves approaching Renew Newcastle to request the involvement of their vacant properties in the tactical urbanism scheme. Media coverage had begun to grow and the benefits of having activated spaces, rather than empty, boarded up windows to show prospective owners or tenants was becoming more and more evident.

illustration 8: Renew Newcastle was listed as one of the ten best travel destinations of 2011 by Lonely Planet.

\section{NEWCASTLE, AUSTRALIA}

For the best part of a century, Newcastle was dominated by its billowing steelworks until their closure in 1999 dealt a massive economic blow. But Novocastrians are a resilient bunch, and the dozen intervening years have seen an explosion of artists taking advantage of the cheap living costs.

Newcastle now has the most artists per capita nationwide, and the most galleries from acclaimed regional centres to independent, artist-run spaces and dozens of disused city-centre buildings occupied by photographers, fashion designers, digital artists and more as part of the inner-city regeneration scheme, Renew Newcastle. Today's 'new' Newcastle is a unique blend of imagination, sophistication and laidback surf culture. -Lonely Planet, 2011

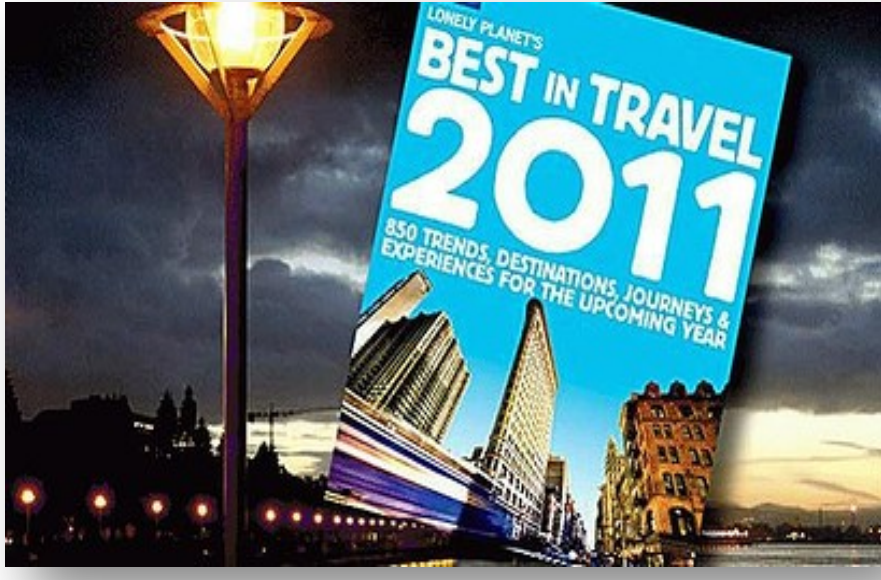

Most Australians were surprised, as Sydney, the largest city, had never been listed. Source: canberratimes.com.au

In 2011, to the surprise of most of Australia, and Westbury himself, the Lonely Planet tourism publication listed Newcastle among the top ten 'Best Trends, Destinations, Journeys \& Experiences' in the world—specifically drawing attention in their entry to the 
success of Renew Newcastle in creating a revitalized, vibrant central core, filled uniquely with artistic, creative and experimental spaces, and the crowds enjoying them.

The achievement of Renew Newcastle reveals an interesting fact of this urban revitalization innovation. Support for tactical interventions crosses political boundaries. Westbury states as much, when he exclaims, "indeed this may in fact be the only project in the history of Newcastle to get praise from the Save Our Rail people and Hunter Permaculture to Hunter Business Chamber and GPT - who were the first large scale property developer to get behind the project" $(2009$, p8).

It must be understood that Renew Newcastle is not solely about artists invading a desolate stretch of a downtown street. Although the model is very amenable to the artistic community's chronic lack of affordable studio and gallery space, the concept would not have achieved the success it has, with such a single-purpose draw. Westbury stresses that a diversity of interests is what he sees as at the core of Renew Newcastle's achievement. The underlying challenge is to create the opportunity for hundreds of 'initiativists' to participate, succeed, perhaps failing, but always learning, as they inject a surge of originality, creativity, and a unique flair into the city, while creating jobs for themselves and others (No author, 2011). What makes this injection much easier to coordinate today is the advent of social media—as seen with the rapid response Westbury experienced once he created a Facebook discussion.

Tanya Toft uses the term "impulsive formation" (2011, p6), to describe the contemporary ability of residents to mobilize, navigate the city, connect and collaborate via social media all the while affecting tangible change in the real world. Online fora 
such as Meetup.com and Facebook Events, where participants from throughout a geographic area are able to arrange real-world social collectives, events and engagements based on shared interests exemplify the ease with which city dwellers today can be brought together.

\subsection{PRACTICE - What has worked in other locations}

The growing application and success of tactical urbanism initiatives in cities throughout the world is demonstrated by the vast diversity of vacant storefront properties uses which attract a diverse flow of visitors to a commercial corridor; just a few examples of these are listed below:

- yoga studios,

- secret restaurants,

- art galleries,

- art studios,

- web and graphic design businesses,

- zine publishers,

- film and video studios,

- retail shops,

- fashion design galleries,

- jewellery workshops,

- milliners,

- photography studios and galleries,

- food co-operatives,

- bicycle and skateboard repair shops

These uses not only demonstrate for Toronto the wide variety of potential participating enterprises but as well, the multiplicity of ways in which unmet needs of 
surrounding communities may be catered to. With the initiative that tactical urbanism requires from local stakeholders to function, those who wish to activate vacant storefronts in Toronto will not necessarily need to simply replicate the above examples. Community participants may provide their own input regarding which enterprises are required or available to satisfy local needs. Many Toronto neighbourhoods were reported in a 2010 policy paper to be chronically lacking in conveniently accessible healthy groceriesreferred to as 'food deserts' — with only $51 \%$ of the city's population being within 1 kilometre of a grocery store (Martin Prosperity Institute, 2010). This represents one example of how local needs may be met by local initiatives. At the same time, municipal authorities could be made aware of such market failures, by the resulting popularity of successful grassroots, tactical interventions that cater to these erstwhile unmet needs.

\subsection{CONCLUSION OF REVIEW}

Toronto is obviously not a Detroit. Toronto does not suffer from the inner-city blight described as afflicting Newcastle in 2008. The tactical intervention described above, however, is not merely applicable to dire situations of urban neglect, or solely during economic downturns. Indeed, after the initial momentum gained in Newcastle, the ongoing opportunities provided by short-term vacancies are much the same in both cities.

The Renew Newcastle program has not ceased operations, even after successfully bringing urban vibrancy (as well as in many instances market-rate tenants) to commercial corridors in downtown Newcastle. The stabilization of the vibrancy of commercial corridors through the presence of 'invisible vacancies', and the incubating opportunities such 
interventions provide are the lessons to be taken away from the success of Renew Newcastle.

Initiative is said to be the capital of the Temporary Urbanist (Arlt, 2004) and Renew Newcastle exemplifies this aphorism, with Westbury celebrating 'initiativists'. Much as in Newcastle, within Toronto too, such entrepreneurial experimenters may be found. We have seen that the ultimate goal of revitalization and injected vibrancy may be reached via differing routes, perspectives and ideologies—whether what is sought is enhanced local economic development and property value appreciation, the creation of opportunities for creative enterprise, the addressing of local market failures, or simply more vibrant commercial corridors. It is intriguing to note that much of Marcus Westbury's experience is replicable here in Toronto. With Australia and Canada possessive of quite similar legal and political systems, understanding the Renew Newcastle experience and the trials and tribulations overcome to achieve success, allows for an accurate perspective on the potential for such an initiative in Toronto.

A significant lesson appears to be that launching the program was in and of itself quite important for its success. Many were only convinced, and willing to participate, whether as property lenders or enterprising participants once they were able to see the program in action. Similarly, planners and policymakers although hesitant and even skeptical initially, eventually joined forces and currently are considered partners with the Renew Newcastle initiative. Such experience is telling, with regard to what would be expected in Toronto. This review of practice assists in communicating with key 
informants the manner in which tactical urbanism works in the real world and the roles played by each stakeholder. 
5.0. TACTICAL URBANISM—seeking opportunity in the idle interim in Toronto

Temporality is defined as "that which exists for a short while or has a short life cycle" (Toft, 2011). The relatively transitory nature of storefront commercial activity is an intriguing and fundamental concept to the practice of urban planning and indeed within city-life itself. Karl Overmeyer, a pioneer in the practice of tactical urbanism in Germany celebrates its potential when reflecting on the fact that "many people consider urbanism something purely physical and formal" (Beeksman 2009). Cities are, in many respects, in constant transition and when city dwellers consider the extent to which even vibrant urban streetscapes are in an interminable state of flux, the organic nature of our downtowns, communities, neighbourhoods and commercial corridors is better perceived. As Jean Hillier succinctly describes, "Planning is the art (or science) of spatial manipulation. It is a mediator in the continuous process of space-becoming or spacing" (2005, p282). The practice of urban planning may at one significant level be described as the exercise of perceiving and guiding the transitory journey of the way in which city dwellers use and enjoy the city. 

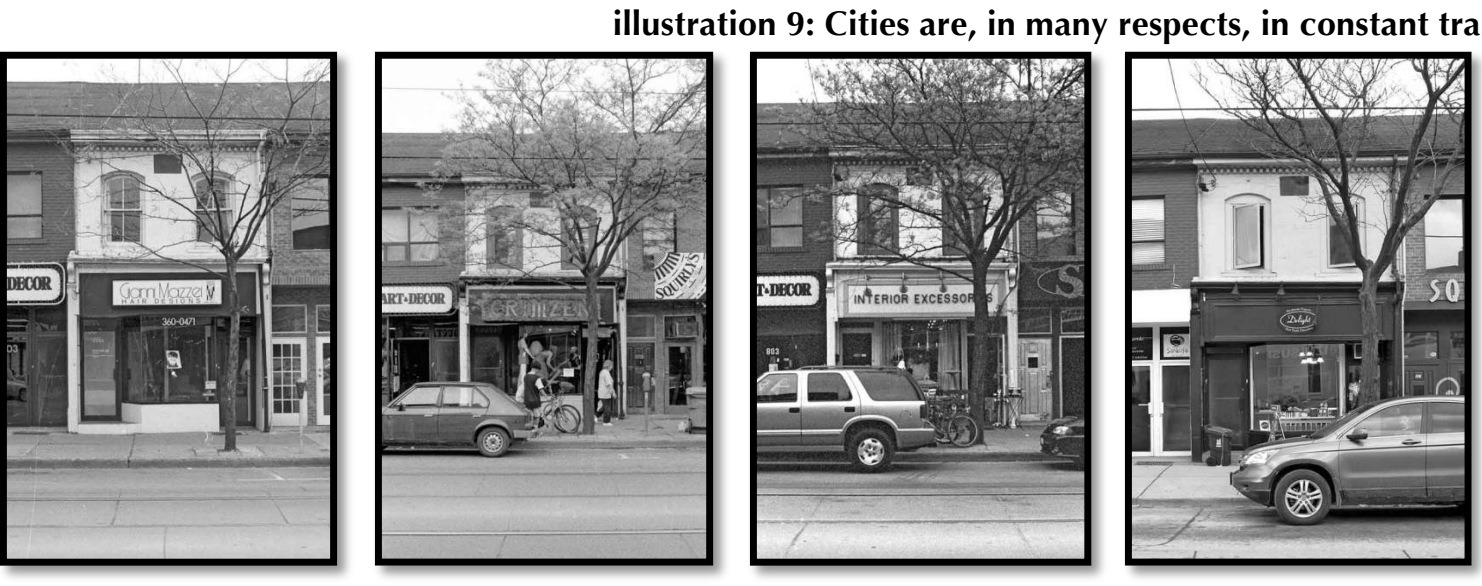

805 Queen Street West in Toronto, photographed in 1987, 1997, 2001 and 2012, respectively. source:

Patrick Cummings

More traditional urban planning initiatives have generally focussed on a lengthier period of transition, such as those found in multi-year master plans. As noted by Haydn \& Temel, "usually, planning is for the long term and not for rapid changes in use" (2006, p17). Tactical urbanism acts as an engagement and intervention within a shorter timeframe-seeking opportunity in the idle interim. The Renew Newcastle example above spoke to idle periods of merely 30 days duration, at minimum. As noted earlier in this paper, attending to the disruptive nature of vacancies acts to forestall or reverse potential trends of more permanence, such as the diminished vibrancy of urban areas; thus avoiding exacerbating condition for neighbouring enterprises. An intriguing aspect of the participation of engaged, concerned community members in such initiatives is the contribution not only of time and labour but that of local knowledge, experience and networking. These qualities are a fundamental component of the concept of tactical urbanism. Shelagh Graham notes that "planners are often in the position of facilitating relationships between actors" (2012, p59)—reflecting the unique role planners are able to 
play between the diverse stakeholders of tactical urbanism initiatives to facilitate community collaboration.

Municipalities may benefit from local community-level intervention confronting economic or social concerns at an earlier stage, or at a more direct level of engagement, than larger bureaucratic efforts may address at a later period. Indeed, in time such concerns, unaddressed, may become an issue for the entire city at large, requiring more 'strategic' interventions.

By forestalling the need for such larger, more intensive and expensive rehabilitation requirements in the future, a city is able to use its financial resources more efficiently in the longer term. Granting community members the agency to address altering neighbourhood realities creates the potential for a strengthened sense of ownership over the fate of a local commercial corridor as well as incentive for the discovery of local solutions.

With such local involvement, opportunities for experimentation arise that otherwise may not have been viable. The idle interim affords the chance to reduce the risks and barriers faced by start-up enterprises, novel commercial ideas, cottage industries and erstwhile hobbies; allowing them to prosper, grow and expand into successful small businesses. Young people and the under-employed may be offered hope by reduced costs or risks of failure. Marcus Westbury of Renew Newcastle revels in the possibilities these circumstances create; the 'possibilities of failure', as he playfully refers to them (Westbury ${ }^{z}$, 2012). Tanya Toft (2011) speaks to the new activities and functions that tactical intervention brings to urban spaces, while at the same time altering the 
psychogeography, or possibilities of place, within the imagination of city dwellers. Tactical initiatives thus act to catalyze the urban development process within ephemeral environments.

Catalysis such as this however requires effort beyond the simple creation of an attractive environment. Tactical interventions are more than the mere decoration of windows with advertisements and attractive displays. The objective of such initiatives is the maintenance or enhancement of the vibrancy of a commercial corridor with enterprising activities meant to draw and engage the public within erstwhile inaccessible, vacant properties. By not merely appearing as an attractive mural or diorama to pass by, pedestrian traffic will indeed be enhanced and commercial activity within a neighbourhood reinforced. When a commercial corridor is in decline, beautification alone will not act to reverse the causal issues at play with regard to the contagion of dereliction, as it may act as only a cosmetic adjustment.

illustration 10: Cosmetic enhancements to empty storefronts alone, fail to enhance vibrancy

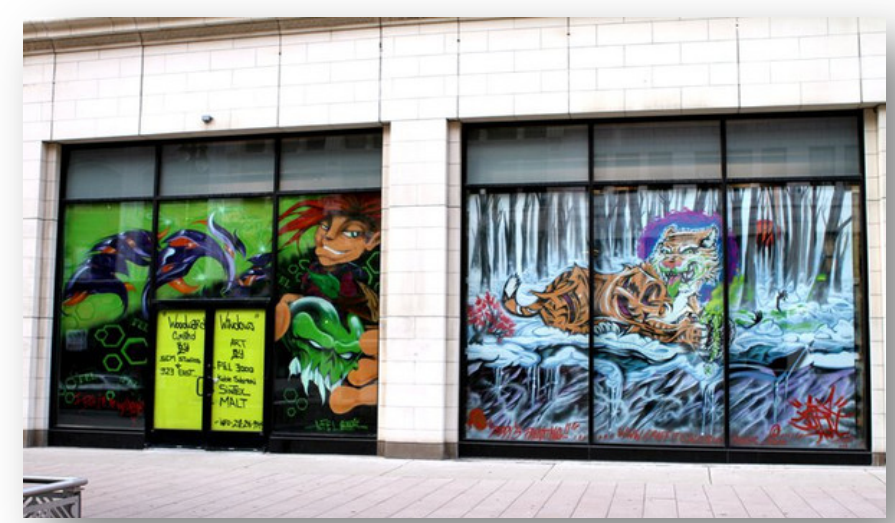

Windows with murals along Woodward Avenue in downtown Detroit. source: 323east.com 
Tactical urbanism seeks to enhance the character of a commercial corridor at an interactive level. Indeed the creation of spaces of encounter within which the public may relate, not merely with formerly unavailable physical areas, but with one another as well, are what underlies the concept of placemaking. Marcus Westbury (2012) vehemently distances himself and his concept from initiatives that attempt to ally themselves with the Renew Australia branding while not truly engaging in interactive placemaking as much as solely placing murals on windows. With the Renew model recognized and lauded throughout Australia today, many groups attempt to gain credibility by claiming affiliation-which in most cases Renew is in no way averse to, but Westbury maintains that they do try to be vigilant regarding endeavours which in any way diminish the public perception and understanding of the purpose and functionality of the Renew model, the revitalization process being fostered by them and the care and organizational work involved in achieving their success.

\subsection{BARRIERS TO ENTRY—what holds Tactical Urbanism back?}

The tactical orientation of citizen-led initiatives aims to alter, diminish or remove barriers to entry that acts to prevent access to idle spaces within a district. Traditionally, these barriers have existed notwithstanding a community's determination to change local circumstances. Creative startups in the past, therefore, have not had the opportunity at enterprise experimentation in these declining environments. In this regard, municipal regulations in many instances can behave as the greatest barriers to entry. Marcus Westbury notes that: "culture, life and commerce works best as an ecology" (2009, p11), 
while regulatory regimes may work to inhibit such organic mixtures of interaction, engagement and collaboration of local civic actors.

\subsubsection{Regulation}

While bureaucratic inertia has been described as one cause of the existence of idle spaces—such as during the periods of delay in development applications, it also may act to preclude the versatility of tactical interventions; when permits for specific activities (such as serving alcohol) are more expensive or necessitate a lengthier process than a very short term stewardship can afford. Marcus Westbury points to the lack of proportionality he discovered where certain compliance costs have totalled $\$ 10,000$ regardless of whether the applicant was a multinational corporation or a local startup (Westbury, 2009).

The necessity for building or development permits—even for relatively unobtrusive, short-term interventions, excessive Occupational Health and Safety guidelines, Heritage property protocols as well as taxation implications upon property owners; all conspire against temporary use initiatives. Westbury decries "the explosion of nanny state regulation, NIMBY (not in my backyard) campaigns, and compliance costs (as) disastrous at the small scale" $(2009, \mathrm{p} 9)$. For this reason, Westbury recommends the simplest interventions-those operating basically that which was already previously permitted on chosen sites—-thus not necessitating further approvals and inspections. 


\subsubsection{Property Owners}

Gaining the participation of property owners a basic requirement-as it may be argued that they are the most important group of stakeholders since they own the sites and without their cooperation nothing can happen. The existence of absentee landlords who are difficult to contact, convince to participate, or who reside overseas, with little investment in the maintenance of vibrancy within the neighbouring community, was found by Renew Newcastle (Westbury ${ }^{Z}$ 2012), to limit the potential for a strong tactical urbanism program. Additionally many property owners may remain skeptical regarding the temporary nature of the occupation and whether startup enterprises would genuinely act responsibly in a space for which they were not paying rent or resist being asked to leave when necessary, after a market-rate alternative tenancy was found. A concern with a rapid transition of tenants, from the perspective of a property owner, may be the false perception of a failed business and thus the implication of a location lacking desirability.

\subsubsection{Systemic Externalities}

Certain influencing factors exist beyond the control of local community and neighbourhood groups. As discussed in Section 3.1 and Brian Berry's (1963) four categories of blight, declines in local commercial corridor vibrancy may be due to questions of access—reductions in transit service; the changing of neighbouring zoning regulations-to introduce non-complimentary uses (industry) rather than residences; the construction of a highway or other form of physical barrier-all of which has the potential 
of resulting in the isolation of specific neighbourhood streets, as well as reductions in property value.

Along with the advent of such land use as industry, arises the new proximity to sources of pollution — whether with regard to air quality, noise or otherwise- -this may occur from the construction of manufacturing operations, highways or airports nearby. The increase of local criminal behaviour, whether caused by larger policy issues (income segregation policies, homelessness or mental healthcare funding), or social problems resulting from a variety of issues which may affect one particular neighbourhood more than others, would similarly be beyond the ability of an individual commercial area to address and confront on its own. Tactical urbanism initiatives would be hard-pressed to achieve success in circumstances where the introduction or attraction of the public is in some way hindered by such extreme, repellent conditions. Significant strategic intervention would be required first, to counter such systemic causes of decline. 


\subsection{THE TORONTO PERSPECTIVE}

illustration 11: Enduring vacancies along Queen Street West create idle spaces on an otherwise vibrant strip

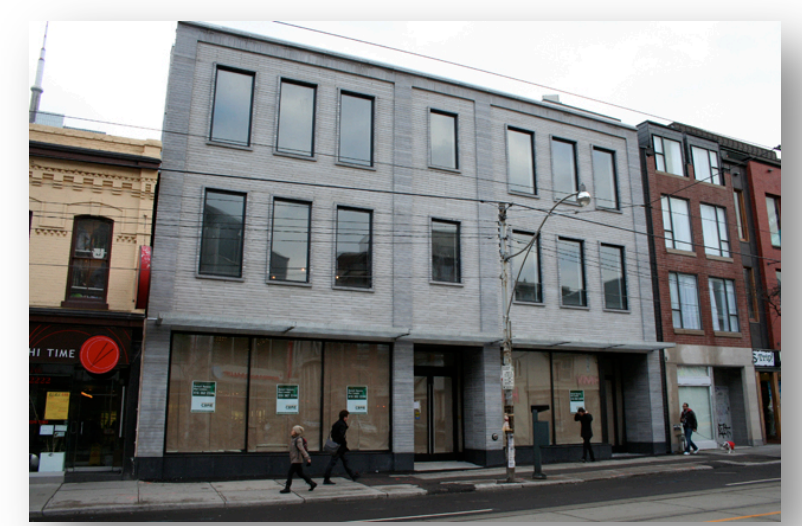

\subsection{INTERVIEWS}

Queen Street West, Toronto Source: The GridTO

Semi-formal interviews were conducted with three citywide organizations as well as convenience-sampled stakeholders within two distinct commercial corridors in the city of Toronto in order to gain an appreciation of the unique perspectives of the anticipated variety of local area stakeholders who would involve themselves in, or be affected by, tactical urbanism initiatives. These stakeholders were comprised of a property owner, a business association and a creative association, from the respective neighbourhoods. In the interest of maintaining the anonymity of the contributing informants for this research project, neither the commercial corridors, nor the participants will be identified explicitly.

The two selected commercial corridors were located along the Queen Street in the urban core of Toronto, one to the east, and one to the west, of the Don Valley, both equidistant from Yonge Street, and served by the same streetcar. Along Commercial Corridor $\mathrm{E}$, an average storefront was renting for $\$ 28$ per square foot, annually, and had 
monthly taxes of $\$ 3800$. Along Commercial Corridor W, an average storefront was renting for $\$ 19$ per square foot, annually, and had monthly taxes of $\$ 2600$ (rates provided by respective property owners. The higher rental rates of Corridor E with respect to Corridor W would imply a more vibrant and popular location. These valuations were said to not be considered constant, as both neighbourhoods were experiencing increasing popularity

\subsubsection{CONCEPT FAMILIARITY}

In all interviews conducted, although some of the informants had heard of the creation of attractive displays and murals on vacant storefronts, none had familiarity with the actual activation of vacant properties in the form of a tactical intervention. Once described, there was an overall enthusiastic response, and anticipation for such a program to be launched in Toronto.

\subsubsection{CITYWIDE ORGANIZATIONS}

An official from an umbrella organization of Business Improvement Associations (BIAs) stated that their group functioned more to lobby the municipal government on behalf of BIAs and are not mandated to participate directly in BIA activities, nor compel BIAs to perform in any specific manner. BIAs in Toronto, due to municipal bylaws, are obligated to invest their revenues within their specific local areas. In this way, Toronto's BIA umbrella organization is more a political resource than a vehicle attempting any participatory revitalization efforts at the citywide level. Having said this, the official expressed enthusiasm for the idea and saw great potential in its application in Toronto. 
A Toronto-wide arts organization consulted regarding their current involvement in the activation of temporary spaces stated that they concentrate on the direct control of larger properties, acting more as a property manager, providing spaces at affordable rents to artistic endeavors. They do not involve themselves with small spaces and limited time engagements, as they lack the resources to administer such projects; limiting themselves to the provision of more permanent spaces and not the programming of them. The contact did mention that although they would not be able to participate directly, it was most likely that many of the small artistic entrepreneurs with whom they work, would definitely be looking to participate in an initiative which brought such affordable, accessible space, and that the Toronto-wide arts organization would hope to network with such a venture.

An organization dedicated to the facilitation of social innovation, start-up incubation and social entrepreneurs networking commented that although they found the idea very innovative and exciting for Toronto and its potential to enhance urban vibrancy, participating directly was not a part of their core mandate, and that they had a limited capacity to administer such projects. The informant expressed great enthusiasm for the potential for future engagement with such an initiative regarding networking amongst other Toronto organizations and potential 'initiativists', but would not be able to be further involved than that. The Renew Newcastle model was seen as having great potential, working with many of the small individual social enterprise initiatives incubated by this agency.

One aspect commented on by the social innovation informant was that of governmental involvement potentially working at cross-purposes to creative, organic 
project incubation—such as that which tactical urbanism interventions seek to catalyze. Governments generally seek formulaic formats, they stated, and there would be a risk of limiting the diversity of conceptualized uses and ideas incorporated as well as the diversity of participants invited to contribute to such tactical endeavours.

\subsubsection{VACANT PROPERTY OWNERS}

Both vacant property owners expressed enthusiasm for the basic concept of having voluntary stewards maintain their property while it remained idle, and contribute to a livelier location as it was shown, although both did raise some concerns and questions.

One specific concern expressed by both property owners contacted was that of liability. With access granted to their properties in the unconventional form of a license agreement, they wondered about not being held responsible for any potential injuries experienced by the public. Additionally, were the property, or the licensee's contents damaged, they wondered if they would be in any way held financially liable. The question of the level and ownership of risk was of primary concern in this regard.

While both landlords appreciated the maintenance and surveillance benefits from the stewardship of their properties, they wondered if there would be difficulties in having the temporary occupants vacate, when more permanent circumstances (buyers, tenants or development) arose. One owner from Corridor $\mathrm{W}$ asked if the disruption from a reversion to a market-rental situation would potentially draw a reaction from the communitywould there be a backlash? Would they be seen as being profit-driven rather than socially engaged? Both property owners interviewed, from either commercial corridor, mentioned 
they would need to trust the organization—a track record, references and past successes would likely assuage their skepticism, they felt.

\subsubsection{BUSINESS OWNERS}

Merchants interviewed within the two selected commercial corridors were of two minds. The business owner from Corridor W stated that the vibrancy and enhanced potential for walk-in traffic were welcomed. A concern however was that of competition with lower overhead costs. With temporary activated projects not paying market rents, they wondered whether their existing businesses would be undercut. They also sought a better understanding of the duration of the projects, as the introduction and departure of these neighbouring establishments would have a potential impact on their businesswhether complimentary or adverse. Business owners in both corridors E and W were enthusiastically appreciative of the potential for enhanced levels of patron traffic and presence, generally, which activated storefronts would provide—creating, or enhancing, a welcoming, safe, active environment.

One merchant in Corridor E stated that a diversity of enterprises is always welcome, and needed. In his opinion it was unfortunate that property owners influence this mix a great deal, through their decisions of to whom to rent, potentially avoiding enterprises perceived as more risky and settling for similar business formats or franchise chains and thereby making every neighbourhood more and more like every other. In this way, he observed, it requires courageous landlords and unorthodox attitudes to truly create districts the public may find attractive and distinctive. 


\subsubsection{BUSINESS ASSOCIATIONS}

Of the two commercial corridors investigated, a BIA was established in Corridor W, while not in Corridor E. The BIA was extremely intrigued by the proposition of a program to enhance vibrancy and diminish the impact of vacant storefronts. Enthused by the potential of a partnership with such an initiative, they valued the local level engagementattempting to improve the neighbourhood using resources within the surrounding community, rather than a top-down city hall led endeavour. The investment of local knowledge was the aspect cited by most merchant, as lacking in unsuccessful revitalization efforts of the past, expressed a BIA official. Every BIA, much as every neighbourhood, is unique; with unique variables of success and failure. It is for this reason, he commented, that citywide initiatives when realized on the street may result in unexpected results.

The business owner in Corridor E stated that local merchants were in the active process of organizing together. With their commercial corridor gaining more and more of a favourable reputation in the city, gaining its own distinct identity, he was surprised that there in fact was no existing BIA there. The local media often reports on Corridor E's recent renaissance and gradual gentrification, and informants from this corridor spoke of this recent evolution, and the overall confidence of his fellow merchants that it would lead to a local BIA and other community-level organized groups quite soon. 


\subsubsection{CREATIVE ASSOCIATIONS}

The two commercial corridors compare very well with regard to the influence of the creative community within the surrounding neighbourhood and their presence at street level. Both corridors boast not only many individual arts-related enterprises, but also distinctive centres of the artistic community, which act as nexuses for the surrounding neighbourhood and the artists along the corridor. It was these centres that were approached for comment. Both informants stated that were a vacant storefront tactical intervention program to operate in their neighbourhood, they would definitely participate.

One concern raised by the creative association representative of Corridor W was the lack of consideration, perhaps even respect, received by the creative community in the evolution of cities. Echoing Alexandra Alter's (2009) critique, referenced earlier, in the Literature Review of this paper, he noted in his decades of experience in the Toronto arts industry, that artists and startup entrepreneurs, while willing to take risks and create pioneering bases in unpopular areas of Toronto, may create more frequented, fashionable atmospheres. Once such districts gain such flavour however, the creative pioneers often may themselves be priced out of an area. The question he posed in this regard was whether tactical urbanism activation projects would consider and address this in any way.

The creative community ought not lose all the fruits of its labour, was his

sentiment. When considering what strategic role the municipal government may have regarding the success of tactical local activation efforts, he cited Chicago specifically, which within its Official Plan and local revitalization schemes guarantees the continuity of proportions of property use-from before the implementation of revitalization programs. 
Such policies act to ensure a segment of pioneering tactical interveners may remain in a district and enjoy the atmosphere of their own creation.

From Corridor E a view was expressed lamenting the fact that the citywide umbrella organization for arts had now become so successful that it had evolved into more a property development organization and was less concerned with smaller creative initiatives. When they attempted to contact larger bodies for assistance during their start up phase, there was little if any response or assistance and thus they launched and organized alone. The creative association in Corridor $\mathrm{W}$ as well as the umbrella business association shared this same sentiment, regarding unfulfilled expectations of the citywide umbrella arts organization, which today though quite well known, is not necessary all that helpful.

One skeptical inquiry from the neighbourhood arts organization in Corridor W was whether tactical urbanism was merely for economic recessions and downturns in the commercial real estate market. What were the 'initiativists' to do were the program and all its assistance, as well as the much-needed spaces, to fold and dry up when time were good, they wondered.

As noted earlier in this paper, the nature of urban life is a constant flux. Whether from new developments that have not yet been occupied, rented or purchased, to storefronts awaiting demolition, which may still be several months away. There also exist areas where property values are increasing with speculative owners who hold out for higher rents, and in so doing, prefer vacancies rather than committing to long-term leases. Thus 
whether a district is experiencing growth or decline, opportunities continue to arise to avail of the idle interim.

\subsection{FINDINGS}

\section{-REGULATION}

An intermediary organization activating vacant storefront spaces—while providing opportunities to those with creative, enterprising ideas and initiative-would be welcomed in Toronto, as seen by the enthusiastic responses of the key informants spoken with. Having said this, many contacted expressed some skepticism and doubt regarding the actual functioning of such an initiative. Significantly, as mentioned in many parts of this paper, there are obstacles with regard to current tax legislation, which create opportunity costs not present in other jurisdictions that have produced successful tactical urbanism initiatives. Other regulatory concerns raised were the fact that BIAs are only permitted to contribute to, and thus in certain ways participate in initiatives in their defined and designated areas. Thus, tactical urbanism initiatives at any scale larger than the boundaries of a BIA would in some ways have limited assistance or cooperation, if any, from local economic development organizations of this kind. In a similar manner, many citywide umbrella agencies are limited by their constitutional mandates and thus would not be able to participate explicitly, although did express the desire for implicit collaboration and networking. 


\section{-PROPERTY OWNERS}

Property owners are obviously able to dictate a great deal regarding the occupancy and activity within each storefront. Gaining the buy-in, and participation of property owners is thus key for success. As seen with the Renew Newcastle experience, with success and the building of credibility, property owners are more likely to be amenable to such initiatives, even after stability is reached along commercial corridors. Both business owners as well as creative associations in both corridors noted that although vacant storefronts are to be found in their neighbourhoods, certain vacant property owners were perhaps holding out for higher rents or purchase prices for their properties, as their corridors had become quite dynamic and popular in the last several years and were in no way in 'decline'. Due to this speculative activity however, the street was experiencing gaps in activity, which were a cause for local concern. Within Toronto, it may be possible to find small pockets of such growth and thus the opportunities for intervention, even though corridors may not be transitioning as dramatically as was evident in the Renew Newcastle example.

\section{-SYSTEMIC EXTERNALITIES}

Although a number of umbrella organizations currently operate in the city, dealing variously with local business development, establishing space for creative enterprises and the fostering of social enterprise, amongst others who were not contacted, none appear to have within their mandate the specific objective of using tactical urbanism initiatives to 
activate vacant storefronts to create opportunities for startup enterprises and the creative community, while sustaining vibrant places.

There was significant enthusiasm in Toronto from the sample of stakeholders contacted for the idea of temporary urbanism. Along with this however is confusion and misapprehension regarding the current property tax regulations and the potential repercussions from being involved in such schemes. From this, the regulatory environment would appear the most formidable variable to define and understand. And as mentioned, the involvement of bureaucratic agencies runs the risk of creating an overly structured and formulaic protocol, which is said to stifle creative, organic projects of this variety. 


\subsection{ADDRESSING THE RESEARCH QUESTIONS}

This section reviews the initial Research Questions posed in section 2.1, evaluating conclusions developed through the course of this research project. Unfortunately, due to the restrictions for securing Ethics approval for the research conducted with public organizations and agencies, the specific names of the informants, and the organizations, that were contacted cannot be divulged. It is hoped that the specific reference to their roles, functions and mandates may convey to the reader a general idea of which organizations participated and are referenced below.

\section{QUESTION ONE:}

Which stakeholders are affected positively and negatively from such revitalization efforts and might they be involved in their implementation?

From the interviews conducted with the city-wide organizations within Toronto, it is apparent that there would be a great deal of mutual benefit gained from tactical urbanism initiatives being implemented in vacant storefronts along commercial corridors of the city. Many of those who work with these organizations, from social entrepreneurs, start-up enterprises, arts groups and local neighbourhood economic development organizations would indeed be those who would appreciate the opportunity to gain access to such previously unavailable, and inexpensive commercial space. As discussed in the section on Inclusive Revitalization, planning interventions always involve those who benefit and those who potentially do not. With the temporary nature of tactical urbanism interventions, commercial corridors and their surrounding communities would 
be experiencing transitional flux. Along with this change, would arise the municipal government's own strategic efforts and more long-term alterations in many aspects of the commercial corridor. At times the ability of tactical urbanism to reorient an area's popularity within a city would necessarily lead to a dearth of potential intervention sites, and thus be considered a 'victim of it's own success' in the eyes of those temporary enterprises who were involved in the original intervention. In addition to this however, it was described both in the literature as well as from speaking with those in the community that such attention, and attempts to 'create more vibrancy' may result in incumbent residents being eventually pushed out due to the forces of what is termed 'gentrification'. Whether this is directly attributable to tactical urbanism interventions, or is a coincidental variable of the organic evolution of a city, would need to be investigated further.

With regard to participation, most local area informants did express interest in about the concept of vacant storefront interventions. At the organizational level however, most citywide organizations (i.e., the citywide umbrella organization of Business Improvement Area groups, the citywide arts promotion organization the organization dedicated to the facilitation of social innovation, start-up incubation and social entrepreneurs networking) conveyed much more willingness to assist at a networking level than being in any way directly involved. 


\section{QUESTION TWO:}

\section{What are some best practices in the effective operation of tactical urbanism programs?}

Enhancing awareness of tactical urbanism is a fundamental requirement. A number of the key local informants expressed concern with the duration of occupancy. The concept of there existing a set inventory of available vacant properties within which to shift participating enterprises when necessary-avoiding inconveniencing property owners - was not immediately clear to those who agreed to interviews. Again, through experimentation and practical experience these ideas are to become clearer to those concerned. With Toronto today witnessing the increased presence of 'impulsive formation' through the adaptive use of newer technologies and tools of communication, and contemporary city life being much more mobile and transient, the shifting of the physical locations of temporary enterprises would not be as disruptive as it may appear to traditional merchants, due to the fact that an online presence would be continually maintained communicating such information to the public. Tanya Toft reminds us of this reality with her reference to how "the phenomenon of nomadic behavior in search for happenings have stretched the urban concept and formed a new sense of time: temporal time" (2011, p3).

The launch of a tactical urbanism endeavour may be a very effective way for some of the concerns and misconceptions in Toronto are to be addressed and alleviated. Awareness of this innovative method of collaborative urban revitalization is currently lacking in the city. Renew Newcastle was started with only a few participating property 
owners and startup enterprises; Marcus Westbury had been concerned about the time it would take for the initiative to achieve the critical mass necessary to maintain a baseline number of properties, gain the buy-in of property owners and widespread patronage from the Newcastle community. Achieving such success with his first few interventions, gaining tremendous media attention, and being approached by larger property management firms to participate in the initiative, surprised him. Such attention and popularity would succeed in conveying to potential participants, how the initiative functioned, while also alleviating skepticism and other concerns expressed by property owners.

\section{QUESTION THREE:}

\section{What Toronto-specific factors help or hinder the implementation of temporary storefront reactivation projects?}

Acknowledging that Toronto is not Newcastle, Australia, its unique reality must be understood and adjusted to in order to foster local success. There is the fact of Toronto being a winter city, which necessarily influences the level of pedestrian activity, and street vibrancy during certain parts of the year. There exists municipal and provincial legislation, which would require a customized initiative abiding by and working around

local restrictions. With municipal government officials expressing their desire to solve the problem of vacant storefronts within the city, policymakers may be found to be receptive to non-governmental actions and to potentially assist with removing, or altering, currently existing obstacles for such an initiative. 
Notwithstanding the distinctive nature of Toronto as a setting in which to start a

Renew Newcastle style initiative, Canada and thus Ontario possesses similar legislation ${ }^{\mathbf{5}}$ with respect to leasing and licensing as Australia and New South Wales. The ability to gain access to vacant properties via licensing agreements is key to the functioning of temporary urbanism programs. The fact that a licensee gains no interest in, or possession of, the property implies the agreement remains a common law matter and not one of stature law, as a property lease would be. With licensors able to revoke a licensee's permission to their property at any time, without notice (as well as there not being any financial transactions for the granting of access) the vacancy status of the property for all intents and purposes ought be maintained.

Section 331 of the City of Toronto Act (2006) addresses vacant commercial property specifically, and unfortunately only deems property 'not in use' as vacant. A municipal law expert consulted by the author during the course of this research project confirmed that as the City of Toronto scrutinizes Section 331 applications quite strictly. The requirement that "no portion of the building or structure (may be) used at any time" (City of Toronto Act, 2006, section 331) would imply that property owners would

\footnotetext{
5 "A licence with respect to real property, is the authority to do an act with respect to the land which would otherwise constitute a trespass. A licence does not pass an interest in the property. Rather it is only a personal privilege with respect to the land."--Pollo v Taylor 2004 ABQB 173

"... (T)herefore ... the transmission of an estate to the tenant is an essential characteristic of the relationship of landlord and tenant. No estate in the land passes to a licensee and this, on the authorities, is the principal distinguishing trait between the two relationships.

"An agreement which confers exclusive possession of the premises as against all the world, including the owner, is a lease, while if it merely confers a privilege to occupy under the owner, it is a license. It is often difficult to determine whether a particular agreement is to be regarded as a lease or a license. Broadly speaking, however, the general concept of a license is that it is a mere permission to occupy the land of another for some particular purpose." --Re Br American Oil and DePass 21 DLR 2d 110 (ONCA, 1960)
} 
necessarily lose the vacant status of their property were they to participate in a tactical urbanism initiative, thus losing the $30 \%$ property tax savings.

Although this may seem an impossible hindrance to participation, there may be many conscientious property owners who would value participating enough to be willing to lose out on the $30 \%$ savings. Additionally, participating temporary enterprises may be requested to pay property owners an equivalent value as a form of rent, seeing as the about would total much less than full rent.

\section{QUESTION FOUR: What implications may tactical urbanism initiatives have on planning policy, municipal regulations? (and vice versa)}

Initiative is said to be the capital of the Temporary Urbanist (Arlt, 2004); this should be valued and incorporated by urban planners and municipal policymakers in efforts to revitalize neighbourhoods and commercial corridors under the threat of decline. Indeed the presence and input of these local tactical forces may result in the alteration of existing planning prerogatives and designs (Groth \& Corijn, 2005). We have seen that the ultimate goal of revitalization and injected vibrancy may be reached via differing routes, perspectives and ideologies - whether what is sought is enhanced local economic development and property value appreciation, the creation of opportunities for creative enterprise or simply more vibrant commercial corridors.

Marcus Westbury speaks of the needed "diversity of scale and approach (as) a vital missing ingredient" $(2009$, p5) in municipal administration, and this is what an 
intermingling of styles of revitalization would encourage. The bureaucratic tradition for one-size-fits-all solutions is currently being challenged by collaborative systems that question the lack of unique responses for unique circumstances.

In Toronto, there is a need to level the playing field with regard to the opportunity costs faced by vacant property owners, and having developments follow a schedule or perhaps establishing the requirement that both possible vacancy scenarios are made available for tactical interventions, it would resolve many of the concerns which residents have raised, and that the city councillors are attempting to address.

Municipalities such as Toronto would do well to lead by example. Temporarily vacant properties owned by the city could be made available for tactical urbanism initiatives (Earls, 2011). Additionally The City of Toronto could create, or assist in the creation of an inventory of vacant storefront properties. "Information such as location, size, condition, previous use, and availability may be recorded and made available to potential temporary users. Such information would be useful in matching land opportunities with prospective users" (Earls, 2011). 


\subsection{RECOMMENDATIONS FOR FUTURE RESEARCH AND PRACTICE}

The title of this paper makes reference to the fact that with current storefront vacancies found in Toronto, there exist missed opportunities within which enterprise experimentation and incubation may be fostered. Access to such conditions where trial and error-the risk indeed of failure would cost nothing, has the potential of stabilizing or revitalizing commercial corridors facing decline, dereliction and potential retail blight.

The potential for secondary usage of vacant or even under-utilized storefront property is immense. Jane Jacobs (1961) made mention decades ago of the 2-shift city, where, rather than have activity and vibrancy exist for only one time of the day, another period may be occupied with different city-dwellers enjoying the same location, and creating a vibrant, secure atmosphere for everyone. This project reveals that there is indeed great potential and enthusiasm for tactical forms of collaboration in engaging with the city at a local level and being involved in its evolution.

Through enhanced levels of informal engagement and inclusionary practicesfacilitated by planning professionals_-perhaps the temporal rhythms of city life may be explored further and injected with vibrancy much as Jane Jacobs anticipated. Whether an intervention is to last between a regular intended purpose or simply afterhours, planners are in a position to encourage dialogue on a street-level understanding of what makes a street vibrant. Those who can contribute unique and informed perspectives are those who inhabit these streets, and experience them on the daily basis. 


\section{RECOMMENDATION 1:}

With tactical urbanism still somewhat of a new idea in North America, as these grassroots interventions are experimented with and implemented more and more here, further literature will be produced, both with qualitative as well as quantitative research, providing a deeper understanding of their successes and failure, their advantages and disadvantages and the ways in which the planning practice participates in this experience. In time, best practices both with regard to tactical as well as strategic responses and legislative alterations should be compared. Quantifiable data defining a correlation between vacant storefronts and commercial corridor vibrancy would go far to convince many who may remain skeptical to qualitative claims, and must be disseminated.

\section{RECOMMENDATION 2:}

All three levels of government already have policies in place to independently encourage many of the individual aspects of tactical storefront activation discussed in this paper. From small business incubation loans, to arts grants; and from urban revitalization programs to economic development incentives_-in addition to many others, all exist today, but are not specifically targeted towards tactical, temporary programming. Lobbying is necessary to create more customized, coordinated forms of governmental assistance to grassroots initiatives with such common objectives. These would not solely be of a financial nature but policy as well.

\section{RECOMMENDATION 3:}


A freely accessible, up-to-date, public inventory of the number of vacant storefront properties as well as the duration of vacancy is vital for Toronto ${ }^{6}$. Such an inventory would not only inform the public of the potential availability of spaces to activate as well as the relative vibrancy of their communities, and, but also allow the City of Toronto and its urban planners to understand the related fiscal ramifications in a simple quantifiable form. With such accessible data, the City would be better able to compare the advantages and disadvantages of tactical urbanism initiatives with relation to tax relief programs.

\footnotetext{
6 The Ryerson Centre for the Study of Commercial Activity maintains a retail database that includes vacancies on an annual basis but accessing it is very expensive.
} 


\subsection{CONCLUSION}

The 'vibrant segues' that tactical urbanism initiatives foster not only provide opportunities for local community involvement and the incubation of small enterprise experimentation but also foster a sense of resiliency in neighbourhood community corridors. This paper has explored the general idea of tactical urbanism with regard to storefront vacancies, as well as its specific applicability to Toronto, Canada.

Urban Planning in 2012 is defined by collaborative, community-organized city-building and revitalization ideals. While concepts of change and transition remain at the heart of the practice of urban planning, the role of planners has been shifting for several decades, with an ever-growing number of stakeholders striving to involve themselves in the formal process of how their cities evolve.

Through the investigation of the practical barriers and opportunities for tactical urbanism in Toronto, and the understanding that the advent of tactical urbanism calls for planners to perform as facilitators, providing professional expertise, rather than solely as regulators, this paper has attempted to highlight a redefinition of the role of city administration, in the quest for inclusive revitalization.

The potential for convergence between the tactical and strategic orientations in city planning, discussed in this paper, may result in future planning practice which seeks out street-level knowledge for a better understanding of local affairs and allow for the 'buying of time,' when formulating and addressing longer term issues of bureaucratic concern.

Toronto benefits today from a diversity of cities worldwide, with the past experience of implementing tactical urbanism initiatives—only a few being spoken to in 
this paper. It is hoped that Toronto may develop a strong, functional, customized, format to promote such engaged commercial corridor stabilization in this great city as well. 


\subsection{APPENDICES}

\subsection{Appendix 1}

\section{Section 331 of the City of Toronto Act, 2006}

\section{Vacant unit rebate}

331. (1) The City shall have a program to provide tax rebates to owners of property that has vacant portions if that property is in any of the commercial classes or industrial classes, as defined in subsection 275 (1). 2006, c. 11, Sched. A, s. 331 (1).

\section{Requirements of program}

(2) A tax rebate program under this section must meet the following requirements:

1. The program shall apply to eligible property as prescribed by the Minister of Finance for the purposes of this section.

2. If the property is in any of the commercial classes, the rebate shall be equal to 30 per cent of the taxes applicable to the eligible property, as determined under clause (12) (b).

3. If the property is in any of the industrial classes, the rebate shall be equal to 35 per cent of the taxes applicable to the eligible property, as determined under clause (12) (b).

4. An application may be made by or on behalf of the owner.

5. The application shall be made to the City by the last day of February of the year following the taxation year in respect of which the application is made or such later date as the Minister of Finance may prescribe, either before or after the expiry of the time limit.

6. Unless otherwise prescribed by the Minister of Finance, an owner or a person on behalf of the owner shall submit one application for a taxation year, except that an interim application may be made for the first six months of the taxation year. 2006, c. 11, Sched. A, s. 331 (2).

\section{Mixed use}

(3) If a portion of a property is classified on the assessment roll in any of the commercial classes and another portion of the property is classified in any of the industrial classes, the portion classified in the commercial classes is deemed to be one property and the portion classified in the industrial classes is deemed to be another property for the purposes of this section. 2006, c. 11, Sched. A, s. 331 (3).

\section{If single percentage established}

(4) If the City has established a single percentage for a year under subsection 278 (4), that percentage applies for the year rather than the percentage set out in paragraph 2 or 3 of subsection (2), as the case may be. 2006, c. 11, Sched. A, s. 331 (4).

\section{Evidentiary requirements}

(5) The program may include evidentiary requirements that must be satisfied for the owner to be entitled to a rebate under this section. 2006, c. 11, Sched. A, s. 331 (5).

\section{Right of access}

(6) For the purposes of verifying an application made under this section, an employee of the City or a person designated by the City, upon producing proper identification, shall at all reasonable times and upon reasonable request be given free access to all property referred to in the application made under this section. 2006, c. 11, Sched. A, s. 331 (6).

\section{Information}

(7) Every adult person present on the property when the person referred to in subsection (6) visits the property in the performance of his or her duties shall give the person all the information within his or her 
knowledge that will assist the person to determine the proper amount of the rebate payable under this section. 2006, c. 11, Sched. A, s. 331 (7).

\section{Request for information}

(8) For the purposes of determining the proper amount of any rebate payable under this section, the City may, by letter sent by mail, served personally or delivered by courier, require the owner or manager of a property referred to in an application under this section to provide any relevant information or produce any relevant records within such reasonable time as is set out in the letter. 2006, c. 11, Sched. A, s. 331 (8).

\section{Return of information}

(9) A person who receives a letter under subsection (8) shall, within the time set out in the letter, provide to the City all the information that is within the person's knowledge and produce all of the records required that are within the person's possession or control. 2006, c. 11, Sched. A, s. 331 (9).

\section{Offence}

(10) Every person who is required to provide information under this section and who defaults in doing so is guilty of an offence and on conviction is liable to a fine of $\$ 100$ for each day during which the default continues. 2006, c. 11, Sched. A, s. 331 (10).

\section{Sharing costs of rebates}

(11) The amount of a tax rebate with respect to a property shall be shared by the City and the school boards that share in the revenue from the taxes on the property in the same proportion as the City and school boards share in those revenues. 2006, c. 11, Sched. A, s. 331 (11).

\section{Regulations}

(12) The Minister of Finance may make regulations,

(a) prescribing the requirements for a property or portion of a property to be eligible property;

(b) respecting how to determine the amount of tax to which the percentages specified in paragraphs 2 and 3 of subsection (2) are to be applied;

(c) respecting the determination of the value of eligible property by the assessment corporation;

(d) prescribing the number or frequency of applications under paragraph 6 of subsection (2);

(e) governing programs under this section, including prescribing additional requirements for those programs, and governing the procedural requirements that those programs must include;

(f) prescribing a date for the purposes of subsections (2), (15) and (20). 2006, c. 11, Sched. A, s. 331 (12).

\section{Rebate to include credit}

(13) The City may credit all or part of the amount of the tax rebate owing to an outstanding tax liability of the owner. 2006, c. 11, Sched. A, s. 331 (13).

\section{Complaint}

(14) A person who has made an application under this section may, within 120 days after the City mails the determination of the amount of the rebate, complain to the Assessment Review Board in writing that the amount is too low. 2006, c. 11, Sched. A, s. 331 (14).

\section{Same, if no determination of rebate}

(15) If the City fails to mail the determination of the amount of the rebate to the applicant within 120 days of the receipt of the application or such later date as the Minister of Finance may prescribe, the applicant may complain in writing to the Assessment Review Board. 2006, c. 11, Sched. A, s. 331 (15).

\section{Determination by the Board}

(16) In a complaint under subsection (14) or (15), the Assessment Review Board shall determine the amount of any rebate owing to the applicant. 2006, c. 11, Sched. A, s. 331 (16). 


\section{Same}

(17) Section 40 of the Assessment Act applies to a complaint under subsection (14), (15) or (24) as if it were an appeal under subsection 40 (1) of that Act, except that the assessment corporation shall not be a party for the purposes of subsection 40 (11) of that Act. 2008, c. 7, Sched. C, s. 7.

\section{Appeal to Divisional Court}

(18) Section 43.1 of the Assessment Act applies to a decision of the Assessment Review Board. 2006, c. 11, Sched. A, s. 331 (18).

\section{Offence}

(19) Any person who knowingly makes a false or deceptive statement in an application made to the City or in any other document submitted to the City under this section is guilty of an offence and is liable on conviction to a fine of not more than an amount that is twice the amount of the rebate obtained or sought to be obtained by the false or deceptive statement except that the fine shall not be less than $\$ 500$. 2006, c. 11 , Sched. A, s. 331 (19).

\section{Interest}

(20) The City shall pay interest, at the same rate of interest that applies under subsection 257.11 (4) of theEducation Act, on the amount of any rebate to which the applicant is entitled under this section if the City fails to rebate or credit such amount within 120 days, or such later date as the Minister of Finance may prescribe, of the receipt of the application or interim application. 2006, c. 11, Sched. A, s. 331 (20).

\section{No fee}

(21) Despite this Act, no fee may be imposed by the City to process an application made under this section. 2006, c. 11, Sched. A, s. 331 (21).

\section{Recovery}

(22) If a rebate is paid under this section and the City determines that the rebate or any portion of the rebate has been paid in error, the City may notify the owner of the property in respect of which the rebate was made of the amount of the overpayment and upon so doing the amount shall have priority lien status and shall be added to the tax roll. 2006, c. 11, Sched. A, s. 331 (22).

\section{Time limitation}

(23) Subsection (22) does not apply unless the City notifies the owner within two years after the application with respect to which the overpayment relates was made. 2006, c. 11, Sched. A, s. 331 (23).

\section{Complaint}

(24) The owner of the property to whom the City sends a notification under subsection (22) may, within 90 days of its receipt, complain to the Assessment Review Board in writing that the amount claimed or any part of it was properly payable as a rebate under this section. 2006, c. 11, Sched. A, s. 331 (24).

\section{Definition}

$\underline{(25)}$ In this section,

"tax" has the same meaning as in section 329. 2006, c. 11, Sched. A, s. 331 (25). 


\subsection{Appendix 2}

\section{Section 364 of the Ontario Municipal Act, 2001}

\section{Vacant unit rebate}

364. (1) Every local municipality shall have a program to provide tax rebates to owners of property that has vacant portions if that property is in any of the commercial classes or industrial classes, as defined in subsection 308 (1). 2001, c. 25, s. 364 (1).

\section{Requirements of program}

(2) A tax rebate program under this section must meet the following requirements:

1. The program shall apply to eligible property as prescribed by the Minister of Finance for the purposes of this section.

2. If the property is in any of the commercial classes, the rebate shall be equal to 30 per cent of the taxes applicable to the eligible property, as determined under clause (12) (b).

3. If the property is in any of the industrial classes, the rebate shall be equal to 35 per cent of the taxes applicable to the eligible property, as determined under clause (12) (b).

4. An application may be made by or on behalf of the owner.

5. The application shall be made to the local municipality by the last day of February of the year following the taxation year in respect of which the application is made or such later date as the Minister of Finance may prescribe, either before or after the expiry of the time limit.

6. Unless otherwise prescribed by the Minister of Finance, an owner or a person on behalf of the owner shall submit one application for a taxation year, except that an interim application may be made for the first six months of the taxation year. 2001, c. 25, s. 364 (2).

\section{Mixed use}

(3) If a portion of a property is classified on the assessment roll in any of the commercial classes and another portion of the property is classified in any of the industrial classes, the portion classified in the commercial classes shall be deemed to be one property and the portion classified in the industrial classes shall be deemed to be another property for the purposes of this section. 2002, c. 22, s. 160.

\section{If single percentage established}

(4) If the council of a municipality, other than a lower-tier municipality, has established a single percentage for a year under subsection 313 (4), that percentage applies for the year rather than the percentage set out in paragraph 2 or 3 of subsection (2), as the case may be. 2001, c. 25, s. 364 (4).

\section{Evidentiary requirements}

(5) The program may include evidentiary requirements that must be satisfied for the owner to be entitled to a rebate under this section. 2001, c. 25, s. 364 (5).

\section{Right of access}

(6) For the purposes of verifying an application made under this section, an employee of a municipality or a person designated by the municipality, upon producing proper identification, shall at all reasonable times and upon reasonable request be given free access to all property referred to in the application made under this section. 2001, c. 25, s. 364 (6).

\section{Information}

(7) Every adult person present on the property when the person referred to in subsection (6) visits the property in the performance of his or her duties shall give the person all the information within his or her knowledge that will assist the person to determine the proper amount of the rebate payable under this section. 2001, c. 25, s. 364 (7). 


\section{Request for information}

(8) For the purposes of determining the proper amount of any rebate payable under this section, the municipality may, by letter sent by mail, served personally or delivered by courier, require the owner or manager of a property referred to in an application under this section to provide any relevant information or produce any relevant records within such reasonable time as is set out in the letter. 2001, c. 25, s. 364 (8).

\section{Return of information}

(9) A person who receives a letter under subsection (8) shall, within the time set out in the letter, provide to the municipality all the information that is within the person's knowledge and produce all of the records required that are within the person's possession or control. 2001, c. 25, s. 364 (9).

\section{Offence}

(10) Every person who is required to provide information under this section and who defaults in doing so is guilty of an offence and on conviction is liable to a fine of $\$ 100$ for each day during which the default continues. 2001, c. 25, s. 364 (10).

\section{Sharing costs of rebates}

(11) The amount of a tax rebate with respect to a property shall be shared by the municipalities and the school boards that share in the revenue from the taxes on the property in the same proportion as the municipalities and school boards share in those revenues. 2001, c. 25, s. 364 (11); 2002, c. 17, Sched. A, s. 67 (1).

\section{Regulations}

(12) The Minister of Finance may make regulations,

(a) prescribing the requirements for a property or portion of a property to be eligible property;

(b) respecting how to determine the amount of tax to which the percentages specified in paragraphs 2 and 3 of subsection (2) are to be applied;

(c) respecting the determination of the value of eligible property by the assessment corporation;

(d) prescribing the number or frequency of applications under paragraph 6 of subsection (2);

(e) governing programs under this section, including prescribing additional requirements for those programs, and governing the procedural requirements that those programs must include;

(f) prescribing a date for the purposes of subsections (2), (15) and (20). 2001, c. 25, s. 364 (12).

\section{Rebate to include credit}

(13) A municipality may credit all or part of the amount of the tax rebate owing to an outstanding tax liability of the owner. 2001, c. 25, s. 364 (13).

\section{Complaint}

(14) A person who has made an application under this section may, within 120 days after the municipality mails the determination of the amount of the rebate, complain to the Assessment Review Board in writing that the amount is too low. 2001, c. 25, s. 364 (14).

\section{Same, if no determination of rebate}

(15) If the municipality fails to mail the determination of the amount of the rebate to the applicant within 120 days of the receipt of the application or such later date as the Minister of Finance may prescribe, the applicant may complain in writing to the Assessment Review Board. 2001, c. 25, s. 364 (15).

\section{Determination by the Board}

(16) In a complaint under subsection (14) or (15), the Assessment Review Board shall determine the amount of any rebate owing to the applicant. 2001, c. 25, s. 364 (16). 
Same

(17) Section 40 of the Assessment Act applies to a complaint under subsection (14), (15) or (24) as if it were an appeal under subsection 40 (1) of that Act, except the assessment corporation shall not be a party for purposes of subsection 40 (11) of that Act. 2008, c. 7, Sched. O, s. 7.

\section{Appeal to Divisional Court}

(18) Section 43.1 of the Assessment Act applies to a decision of the Assessment Review Board. 2001, c. 25, s. 364 (18).

\section{Offence}

(19) Any person who knowingly makes a false or deceptive statement in an application made to a municipality or in any other document submitted to a municipality under this section is guilty of an offence and is liable on conviction to a fine of not more than an amount that is twice the amount of the rebate obtained or sought to be obtained by the false or deceptive statement except that the fine shall not be less than $\$ 500.2001$, c. 25 , s. 364 (19).

\section{Interest}

(20) The municipality shall pay interest, at the same rate of interest that applies under subsection 257.11 (4) of theEducation Act, on the amount of any rebate to which the applicant is entitled under this section if the municipality fails to rebate or credit such amount within 120 days, or such later date as the Minister of Finance may prescribe, of the receipt of the application or interim application. 2001, c. 25, s. $364(20)$.

\section{No fee}

(21) Despite this Act, no fee may be imposed by a municipality to process an application made under this section. 2001, c. 25, s. 364 (21).

\section{Recovery}

(22) If a rebate is paid under this section and the municipality determines that the rebate or any portion of the rebate has been paid in error, the municipality may notify the owner of the property in respect of which the rebate was made of the amount of the overpayment and upon so doing the amount shall have priority lien status and shall be added to the tax roll. 2001, c. 25, s. 364 (22); 2002, c. 17, Sched. A, s. 67 (2).

\section{Time limitation}

(23) Subsection (22) does not apply unless the municipality notifies the owner within two years after the application with respect to which the overpayment relates was made. 2001, c. 25, s. 364 (23).

\section{Complaint}

(24) The owner of the property to whom the municipality sends a notification under subsection (22) may, within 90 days of its receipt, complain to the Assessment Review Board in writing that the amount claimed or any part of it was properly payable as a rebate under this section. 2001, c. 25, s. 364 (24).

\section{Interpretation}

(25) In this section, "tax" has the same meaning as in subsection 361 (12). 2006, c. 32, Sched. A, s. 149. 


\subsection{Appendix 3}

\section{TIII TORONTO \\ numbers asion \\ City Council}

\section{Notice of Motion}

Re-designing the Commercial Tax Relief program as a strategic tax incentive to stimulate economic development - by Councillor Mike Layton, seconded by Councillor Mary Fragedakis

* Notice of this Motion has been given. * This Motion is subject to referral to the Economic Development Committee. A two thirds vote is required to waive referral.

Recommendations

Councillor Mike Layton, seconded by Councillor Mary Fragedakis recommends that:

1. City Council request the General Manager of Economic Development and Culture to report to the Economic Development Committee at its meeting on January 26, 2012 on the financial impacts of Toronto's current Vacant Commercial Tax Relief program and possible changes required to use this tax incentive program to stimulate economic development, including through an Enterprise Incubation alternative program for small businesses and not-for-profits.

\section{Summary}

Toronto needs to look for new ways to promote small businesses across our City. From Rexdale to Little Italy, Agincourt to Leaside, many storefronts on our main streets are sitting unused and derelict. One reason they remain empty is that the city, through the Vacant Commercial Tax Relief program, provides a tax subsidy to landlords without tenants for an open-ended period, while many entrepreneurs, budding small businesses and social enterprises are not able to pay the high rents demanded by many of these property owners. While the landlords should be granted some leniency for vacant units, the Vacant Commercial Tax Relief program should not simply support real estate speculation, but instead it should be used as an incentive to stimulate economic development as recommended in the Toronto Prosperity Initiative (Recommendation A.4).

Currently the city grants 30 percent tax relief to storefronts vacant for longer than 90 days, without any corresponding benefit returned to the city. This has the potential to create a disincentive to property owners to fill their vacancies. The mandate of the Economic Development Committee is to enhance the economic environment of Toronto and increase tax revenues to the City of Toronto. It is incumbent upon the Committee to investigate means with which to encourage healthy commercial street life, vibrant neighbourhood retail and evaluate whether current programs prevent that in any way.

\section{MM10.10 ACTION Ward: All}

With simple policy changes from the provincial government, the current commercial property tax relief program could be changed to encourage the support of small business start-ups, artists, community outreach, not-for-profits and other qualifying ventures, within these otherwise empty spaces by way of an Enterprise Incubation program in which property owners would need to register and make available their vacant properties in order to receive property tax relief.

Such a program's ability to increase the flow of patrons may indeed result in an economic boost for depressed areas, diminishing original sources of decline were they local in context. At the very least it would contribute to the reduction of local impacts of more general downturns in the economy. Programs encouraging the temporary use of vacant commercial space have been successfully deployed in a variety of 
cities throughout the world, including New York City, Washington D.C., and Newcastle, Australia. (Submitted to City Council on July 12 and 13, 2011 as MM10.10)2 


\subsection{Appendix 4 \\ TIII TORONTO}

Economic Development Committee consideration on September 14, 2011

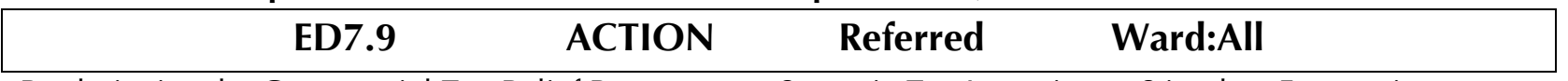

Re-designing the Commercial Tax Relief Program as a Strategic Tax Incentive to Stimulate Economic Development

\section{Committee Decision}

The Economic Development Committee referred Item ED7.9 to the General Manager, Economic

Development and Culture, for a report to the Economic Development Committee on January 26, 2012.

\section{Origin}

(July 19, 2011) Member Motion from City Council

\section{Summary}

Toronto needs to look for new ways to promote small businesses across our City. From Rexdaleto Little Italy, Agincourt to Leaside, many storefronts on our main streets are sitting unused and derelict. One reason they remain empty is that the city, through the Vacant Commercial Tax Relief program, provides a tax subsidy to landlords without tenants for an open-ended period, while many entrepreneurs, budding small businesses and social enterprises are not able to pay the high rents demanded by many of these property owners. While the landlords should be granted some leniency for vacant units, the Vacant Commercial Tax Relief program should not simply support real estate speculation, but instead it should be used as an incentive to stimulate economic development as recommended in the Toronto Prosperity Initiative (Recommendation A.4).

Currently the city grants 30 percent tax relief to storefronts vacant for longer than 90 days, without any corresponding benefit returned to the city. This has the potential to create a disincentive to property owners to fill their vacancies. The mandate of the Economic Development Committee is to enhance the economic environment of Toronto and increase tax revenues to the City of Toronto. It is incumbent upon the Committee to investigate means with which to encourage healthy commercial street life, vibrant neighbourhood retail and evaluate whether current programs prevent that in any way.

With simple policy changes from the provincial government, the current commercial property tax relief program could be changed to encourage the support of small business start-ups, artists, community outreach, not-for-profits and other qualifying ventures, within these otherwise empty spaces by way of an Enterprise Incubation program in which property owners would need to register and make available their vacant properties in order to receive property tax relief.

Such a program's ability to increase the flow of patrons may indeed result in an economic boost for depressed areas, diminishing original sources of decline were they local in context. At the very least it would contribute to the reduction of local impacts of more general downturns in the economy. Programs encouraging the temporary use of vacant commercial space have been successfully deployed in a variety of 
cities throughout the world, including New York City, Washington D.C., and Newcastle, Australia.

(Submitted to City Council on July 12 and 13, 2011 as MM10.10)

\section{Background Information}

(July 19, 2011) Member Motion from City Council on Re-designing the Commercial Tax Relief Program as a Strategic Tax Incentive to Stimulate Economic Development

(http://www.toronto.ca/legdocs/mmis/2011/ed/bgrd/backgroundfile-39798.pdf)

\section{Communications}

(September 14, 2011) E-mail from Peter Clarke (ED.New.ED7.9.1)

\section{Motions}

Motion to Refer Item moved by Councillor Mary Fragedakis (Carried)

That the Economic Development Committee refer Item ED7.9 to the General Manager, Economic

Development and Culture, for a report to the Economic Development Committee on January 26, 2012. 


\subsection{Appendix 5 \\ RTIITORONTO \\ Member Motion \\ City Council}

\section{Notice of Motion}

'Unfinished Business' - by Councillor Paula Fletcher, seconded by Councillor Adam Vaughan

* Notice of this Motion has been given. * This Motion is subject to referral to the Planning and Growth Management Committee. A two-thirds vote is required to waive referral.

\section{Recommendations}

Councillor Paula Fletcher, seconded by Councillor Adam Vaughan, recommends that:

\begin{tabular}{|lll}
\hline MM22.10 ACTION Ward:All \\
\hline
\end{tabular}

1.

City Council request the Chief Building Official and the Acting Chief Planner to submit a report to Council, through the Planning and Growth Management Committee, such report to include the following:

a. b. c.

a review of options available to compel movement from developers where limited progress has been made within a reasonable time frame;

recommendations to Council on the best means of ensuring developments are completed in a timely manner; and

any other options available for the City to pursue to seal or complete such developments should the developer fail to do so.

\section{Summary}

Commercial and residential developments are necessary and important components of Toronto's growth. However, the regulations surrounding development must meet the needs of the neighbourhood and community, as well as the developers. Developers are able to maintain permits for years while no progress is made and no completion is in sight, leaving residents and visitors to wonder why the work is never completed.

Building permits are allocated based on the assumption that the developer will carry out the construction in a timely and efficient manner. Unfortunately, current by-laws allow developers to continue to hold a permit even when progress has stalled beyond reasonable limits.

(Submitted to City Council on April 10 and 11, 2012 as MM22.10) 


\subsection{REFERENCES}

Alter, Alexandra. (April 17, 2009). Artists vs. Blight. The Wall Street Journal. At http://online.wsj.com/article/SB123992318352327147.html. (Accessed 31 January 2012).

Arlt Peter. (2004). Urban Planning and Interim Use. Temporary Urban Spaces: Concepts for the Use of City Spaces. Birkhauser: Berlin.

ArtPlace. (2011). Invitiation for Letter of Inquiry. September 15, 2011. At http://www.artplaceamerica.org/wp-content/uploads/2011/10/LOI-Guidelines_Updated-FAQ.pdf. (Accessed 31 January, 2012)

Beekmans, Jeremy. (June 27, 2009). Klaus Overmeyer on the Importance of Urban Pioneers. The Pop-up City. Retreived March 15, 2012 from: http://popupcity.net/2009/06/klaus-overmeyer-on-the-importance-ofurban-pioneers/

Blumner, Nicole. (2006). Planning for the Unplanned. Occasional Paper for the German Institute of Urban Affairs / Deutsches Institut für Urbanistik. At http://www.difu.de/dokument/planning-for-theunplanned-tools-and-techniques-for-interim.html. (Accessed 31 January 2012).

Breger, G.E. (1967). The Concept and Causes of Urban Blight. Land Economics. Vol. 43, No. 4. pp. 369-376.

Camponeschi, Chiara. (2010). The Enabling City: Place-Based Creative Problem Solving and the Power of the Everyday. Major Portfolio Research, York University. Toronto. Creative Commons.

Camponeschi ${ }^{2}$, Chiara. (January 4, 2012). A Conversation with Chiara Camponeschi. MIT CoLab Radio. At http://colabradio.mit.edu/a-conversation-with-chiara-camponeschi/. (accessed 31 January 2012)

Camponeschi ${ }^{3}$, Chiara. (January 5, 2012). Pop-Up Democracy. Here and Now: Cbc Radio One Toronto. At http://www.cbc.ca/hereandnowtoronto/episodes/2012/01/05/pop-up-democracy/ . (accessed 31 January 2012)

Camponeschi ${ }^{4}$, Chiara. (2011). Panel discussion on Tactical vs. DIY Urbanism. At http://thewhereblog.blogspot.com/2011/10/liveblogging-tactical-urbanism-salon.html. (accessed 31 January 2012).

City of Toronto Budget Committee. (2010). 2010 Property Tax Rates And Implementing 'Enhancing Toronto's Business Climate'. Presentation. March 26, 2010.

Cushman \& Wakefield. (2012). Marketbeat Retail Snapshot. Fourth Quarter Research Publication.

Duhaime, Lloyd. (2009). License v Lease: Distinguishing the Oft-Indistinguishable. Website: Duhaime.org: Legal Resources: Real Estate \& Tenancy. Retrieved March 15, 2012, from: http://www.duhaime.org/LegalResources/RealEstateTenancy/LawArticle-573/License-v-Lease-Distinguishing-the-OftIndistinguishable.aspx

Earls, Matthew. (2011). An Introduction To Temporary-Use: Strategic Planning In The Interim. (Graduate dissertation). Retrieved from the ProQuest Dissertations and Theses database. (UMI Number: 1491988)

Flack, Derek. (February 11, 2011). A Visual History of Yonge and Queen. BlogTO.com. At http://www.blogto.com/city/2011/02/a_visual_history_of_yonge_and_queen_/ (accessed 31 January 2012). 
Fletcher, Paula (2012). 'Unfinished Business' - by Councillor Paula Fletcher, seconded by Councillor Adam Vaughan. City of Toronto Council Motion. (Submitted to City Council on April 10 and 11, 2012 as MM22.10)

Fofrich, Jason Allen. (2004). Experiencing the City: Bringing Life Back to the Downtown. (Masters Thesis.) University of Cincinnati.

Fraker, H. (2007). Where is the design discourse? Places. Vol. 19. No. 3, pp 61 - 63. At http://places.designobserver.com/media/pdf/Where_is_the_U_476.pdf (accessed 31 January 2012).

Graham, Sheila. (2012). Temporary Uses as Tools for Urban Development. (Masters Thesis.) University of Manitoba.

Groth, Jacqueline \& Eric Corijn. (2005). Reclaiming Urbanity: Indeterminate Spaces, Informal Actors, and Urban Agenda Setting. Urban Studies. Vol. 42. No. 3, pp $503-526$.

Havemann, Antje \& (Macute)argit Schild. (2007). 'You can use my tights' or: The phenomenon of temporary solutions. Landscape Research. Vol. 32. No.1. pp 45-55.

Hentila, Helka-Liisa. (2003). Central Micro-Peripheries: Temporary uses of Central Residual Spaces as Urban Development Catalysts. Paper presented in ERSA 2003 Congress. Jyvaskyla 27.-30.8.2003.

Jacobs, J. 1958. 'Downtown is for People'. Fortune, April 1958. Reprint in The Editors of Fortune. 1958. The Exploding Metropolis. New York: Doubleday \& Company. Pp 157-184.

Hillier, Jean. (2005). Straddling the post-structural abyss: Between transcendence and immanence? Planning Theory. Vol. 3. No. 3. Pp 271-299.

Hodge, Gerald. (1991). Planning Canadian Communities. Scarborough. Nelson Canada.

Jacobs, Jane. (1958). Downtowns are for people. Fortune. pp. 157-184

Jacobs, Jane. (1961). Death and life of great American cities. New York. Random House.

Jacobs, Allan. B. (1985). Looking at Cities. Cambridge, Mass. Harvard University Press.

Johansson, Marjana. (2011). City festivals: creativity and control in staged urban experiences. European Urban and Regional Studies. Volume:18. Page: 392.

Kahn, Lauren. Et al. (2009). Breakthrough Cities:How Cities Can Mobilise Creativity And Knowledge To Tackle Compelling Social Challenges. Creative Cities. British Council.

Kelling, George L., James Q Wilson. (March 1982). Broken Windows. The Atlantic. At http://www.theatlantic.com/magazine/archive/1982/03/broken-windows/4465/. (accessed 31 January 2012).

Layton, Mike (2011). Re-designing the Commercial Tax Relief program as a strategic tax incentive to stimulate economic development - by Councillor Mike Layton, seconded by Councillor Mary Fragedakis. City of Toronto Council Motion. (Submitted to City Council on July 12 and 13, 2011 as MM10.10)

Lefebvre, Henri. 'The Production of Space.' Carlton: Donald+Nicholson Smith, 1991. 
Lonely Planet. (2010). Lonely Planet's Best in Travel 2011: The Best Trends, Destinations, Journeys \& Experiences for the Upcoming Year

Lydon, M., Bartman, D., Woudstra, R. \& Khawarzad, A. (no date). Tactical Urbanism (Vol. 1.) At http://streetplans.org/research_and_writing.php. (accessed 31 January 2012).

Lynch, Kevin. (1960). The Image of the City. Cambridge, Mass.: The MIT Press.

Martin Prosperity Insititute. (2010). Food Deserts and Priority Neighbourhoods in Toronto. Rotman School of Management. University of Toronto.

McBride, Jason. (2010). The All-New Downtown. Toronto Life. February 2010. Pages: 40-47.

Mean, Melissa \& Charlie Tims. (2005). People make places: Growing the public life of cities. London, UK. Demos.

Michael Brandman Associates. (2011). Redlands Crossing Center: Draft Environmental Impact Report. City of Redlands. November 21, 2011. At

http://cityofredlands.org/node/366. (accessed 31 January 2012).

Moe, Richard \& Carter Wilkie. (1997). Changing Places: Rebuilding Communities in the Age of Sprawl. New York, NY. Henry Holt \& Company Inc.

No Author. (October 28, 2011) Newcastle Renew project shows the way. The Press.

Westbury, Marcus. (2009). Creative Initiative: Culture, Democracy and Change - Hunter Valley Research Foundation Lecture.

Ontario Ministry of Municipal Affairs and Housing. (no date). Citizens' Guide to Land-use Planning. At http://www.mah.gov.on.ca/Page338.aspx. (accessed 31 January 2012).

Overmeyer, Klaus. (2007) Urban Pioneers: Temporary Use and Urban Development in Berlin.

Senatsverwaltung fur Stadtentwicklung.

Porter, David. (2008). Western Lights: A Purchase, Redevelopment and Debt Stress Analysis. Johns Hopkins University.

Riano, Quillian. (2011). Panel discussion on Tactical vs. DIY Urbanism. At

http://thewhereblog.blogspot.com/2011/10/liveblogging-tactical-urbanism-salon.html. (accessed 31 January 2012).

Sassen, Saskia. (June 29, 2011). The New York City Reader: A Newspaper of Public Space. At http://www.newcityreader.net/issue15.html . (accessed 31 January 2012).

Sutton, Stacey A. (2010). Rethinking Commercial Revitalization: A Neighborhood Small Business Perspective. Economic Development Quarterly. Volume: 24 Issue: 4. Pages: 352-371.

Temel, Robert. (2004). The Temporary in the City. Temporary Urban Spaces: Concepts for the Use of City Spaces. Birkhauser: Berlin. 
Toft, Tanya (2011). Ephermeral City: The Cultural Logics of Temporary Urban Environments. EURA Conference 2011, The Limitless City: Conceptualizing Cities. Department of Arts and Cultural Studies, Copenhagen University, Denmark.

Urban Catalyst. (2003). Urban Catalysts: Strategies for temporary uses - potential for development of urban residual areas in European metropolises. Berlin, Germany.

Westbury, Marcus. (2009). Creative Initiative: Culture, Democracy and Change - Hunter Valley Research Foundation Lecture.

Westbury ${ }^{\text {, }}$ Marcus. (2012, March 6). Personal interview.

Whysall, Paul. (2011). Managing decline in inner city retail centres: From case study to conceptualization. Local Economy. Volume: 26. Issue: 1. Pages: 3-17. 